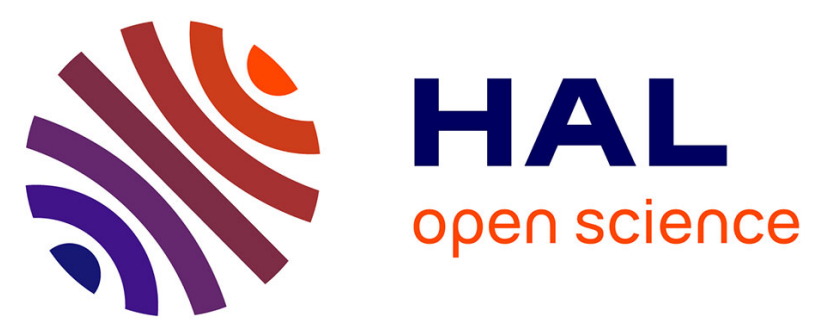

\title{
Nano-films of carbo-benzene derivatives: Scanning probe microscopy analysis and prospects of use in organic solar cells
}

Irving Caballero-Quintana, Julio Rivera-Taco, Cécile Barthes, Juan Nicasio-Collazo, Gabriel Ramos-Ortíz, José-Luis Maldonado, Valérie Maraval, Remi Chauvin

\section{To cite this version:}

Irving Caballero-Quintana, Julio Rivera-Taco, Cécile Barthes, Juan Nicasio-Collazo, Gabriel Ramos-Ortíz, et al.. Nano-films of carbo-benzene derivatives: Scanning probe microscopy analysis and prospects of use in organic solar cells. Synthetic Metals, 2021, 278, pp.116826. 10.1016/j.synthmet.2021.116826 . hal-03260925

\section{HAL Id: hal-03260925 \\ https://hal.science/hal-03260925}

Submitted on 15 Jun 2021

HAL is a multi-disciplinary open access archive for the deposit and dissemination of scientific research documents, whether they are published or not. The documents may come from teaching and research institutions in France or abroad, or from public or private research centers.
L'archive ouverte pluridisciplinaire HAL, est destinée au dépôt et à la diffusion de documents scientifiques de niveau recherche, publiés ou non, émanant des établissements d'enseignement et de recherche français ou étrangers, des laboratoires publics ou privés. 


\title{
Nano-films of carbo-benzene derivatives: scanning probe microscopy analysis and prospects of use in organic solar cells
}

\author{
Irving Caballero-Quintana ${ }^{\mathrm{a}, 1}$, Julio Rivera-Taco ${ }^{\mathrm{a}, \mathrm{b}}$, Cécile Barthes ${ }^{\mathrm{c}}$, Juan Nicasio-Collazo ${ }^{\mathrm{a}}$, \\ Gabriel Ramos-Ortíz ${ }^{\mathrm{a}}$, José-Luis Maldonado ${ }^{\mathrm{a}^{*}}$, Valérie Maraval $^{\mathrm{c}^{*}}$, Remi Chauvin $^{\mathrm{c}^{*}}$ \\ ${ }^{a}$ Research Group of Optical Properties of Materials (GPOM), Centro de Investigaciones en \\ Óptica, A.P. 1-948, 37150 León, Gto., México. \\ ${ }^{b}$ Universidad Nacional de San Agustín de Arequipa, C.P. 04001 Arequipa, Perú. \\ ${ }^{c}$ LCC, CNRS \& University of Toulouse, 205 route de Narbonne, BP44099, 31077 Toulouse \\ Cedex 4, France. \\ ${ }^{1}$ Current postdoctoral fellow at Department of Physics and Astronomy, University of California, \\ Irvine, CA, 92697, USA. \\ * E. Mail: lmr@cio.mx, valerie.maraval@1cc-toulouse.fr, $\underline{\text { remi.chauvin@1cc-toulouse.fr }}$
}

\begin{abstract}
Three carbo-mer derivatives based on a $\mathrm{C}_{18} \mathrm{Ph}_{4}$ core decorated with two identical electro-active groups $\mathrm{X}$, i.e. two aromatic carbo-benzenes ( $\mathbf{1}$ and $\mathbf{2}, \mathrm{X}=4$-anilinyl) and one pro-aromatic carboquinoid (the carbo-TTF 3, X = 1,3-dithiol-2-ylidene) were studied through Scanning Probe Microscopies (SPMs). Self-Assembled Monolayers (SAMs) were fabricated (thickness $\sim 160 \mathrm{pm}$ ), for the two centrosymmetric representatives $\mathbf{1}$ and $\mathbf{3}$, the organization of which on the HOPG substrate was found to be structure-specific. Electrical/electronic properties of the three carbomers were determined by using Atomic Force Microscopy (AFM) and its electrical modes: Kelvin Probe Force Microscopy (KPFM) and conductive Atomic Force Microscopy (c-AFM). Measurements of the work function $(\varnothing)$ through KPFM result in a $\varnothing=5.60 \mathrm{eV}$ value for $\mathbf{1}, 4.97$ $\mathrm{eV}$ for 2 and $4.82 \mathrm{eV}$ for $\mathbf{3}$. Hole mobility $(\mu)$ values extracted from local $I-V$ plots by using c$\mathrm{AFM}$ are $15 \times 10^{-8} \mathrm{~cm}^{2} V^{-1} \mathrm{~s}^{-1}$ for $\mathbf{1}, 3 \times 10^{-6} \mathrm{~cm}^{2} V^{-1} \mathrm{~s}^{-1}$ for 2 and $87 \times 10^{-8} \mathrm{~cm}^{2} V^{-1} \mathrm{~s}^{-1}$ for 3 . A concept test of the possible application of carbo-mers in self-assembled hole transporting monolayer (SA-HTM), with the view to replacing the most common p-type contact used in organic solar cells (OSCs), PEDOT:PSS, is also reported.
\end{abstract}


Keywords: Carbo-mers, scanning probe microscopy analysis, SAMs as hole transport layer, organic solar cells

\section{Introduction}

The nanoscale structure of molecules and their local electronic properties can be studied by scanning probe microscopies or SPMs, general abbreviation for various techniques using probe instruments, mainly scanning tunneling microscopy (STM) and atomic force microscopy (AFM), which are ideal to study 2D materials [1, 2]. Based on the interaction between a fine probe tip in proximity to a sample, surface morphological issues, electrical and electronic properties can thus be finely investigated [1,2]. For instance, STM has been used for imaging the process of selfassembled molecular systems, revealing the parameters involved in monolayer formation: physical parameters (i.e., concentration of solutes, wettability, contact angles, surface tension, temperature) and chemical parameters (i.e., molecular structure, orbital configuration) [3]. On the other hand, AFM is regularly used to characterize morphology of the bulk heterojunction (BHJ) blend in organic solar cells (OSCs) [4]. Besides AFM surface topography measurements, various electrical modes of AFM, such as Kelvin probe force microscopy (KPFM) and conductive-AFM (c-AFM), play an increasing role in understanding the influence of the nanoscale morphology of optoelectronics devices [4]. J. Lee et al. [5], used KPFM to study the internal potential distribution of the PCDTBT:PCBM-based OSCs active film, demonstrating the usefulness of this non-invasive approach for quantifying and mapping local differences in electrical performance due to structural heterogeneities. Likewise, by using c-AFM measurements, topography and current maps of perovskite solar cells (PSCs) were compared to analyze how the perovskite grain size affects the device conversion efficiency [6].

Very recently, OSCs have reached a power conversion efficiency (PCE) over 18\% [7, 8]. In conventional OSC architecture, the transparent anode electrode is generally coated with a p-type material as hole transport layer (HTL) -the most frequently used HTL being PEDOT:PSS-, which prevents a direct contact between the anode and the active layer, thus reducing electrical charge recombination and maximizing the extraction of holes towards the anode for a higher overall performance $[9,10]$. However, PEDOT:PSS has several limitations that can severely compromise 
the stability of the devices: for example, the chemical interaction between PEDOT:PSS and ITO (indium-tin oxide, one of the most used transparent electrodes) causes the corrosion of ITO due to acidity, and further, the hygroscopic nature of PEDOT:PSS can reduce the device performance [11]. Therefore, the search for new HTL materials to replace PEDOT:PSS is of growing interest. Recently, graphene, as a 2D material, has gained noteworthy attention because it possesses excellent intrinsic properties, such as high thermal conductivity, transparency, and high electricalcharge mobility [11, 12]. Several groups have used graphene derivatives as HTL in OSCs [11-16]. In this context, self-assembled monolayers (SAMs) of organic molecules, as 2D sheets, have also been considered as an alternative to conventional HTLs [17]. The main advantage of SAMs is the ability to tune the electrical properties of the surface on which they are attached, the modulation of the work function allows a proper energy alignment between the electrode and the active layer [18]. Alternative HTLs based on small molecular materials as SAMs have been used in solar cells showing similar or even higher PCE values than when using PEDOT:PSS [8, 17, 18].

Besides graphene and graphene oxide derivatives, attractive for their transparency and charge carrier properties, other carbon- and electron-rich molecules, namely carbo-mers [19], are envisaged for the formation of SAMs. Carbo-mers constitute a family of carbon-enriched molecules that are formally obtained by systematic insertion of $\mathrm{C}_{2}$ units into each (or a selected part) of the covalent bonds for a representative Lewis structure of any parent molecule [19]. Ring carbo-mers of benzenic derivatives have been thoroughly studied during the last 20 years, at both the theoretical and experimental levels, and were shown to exhibit unique features making them attractive for several applications [20-22]. In particular, the planar hexagonal $\pi$-conjugated $\mathrm{C}_{18}$ macrocycle of carbo-benzenes confers them, depending on their substituents, linear and nonlinear optical [23-25], mesogenic or conductive properties [26, 27]. The charge transport properties of carbo-benzenes, associated with their flat flexible "carbo-aromatic" structure [21], still deserve further investigations, in particular regarding the formation of SAMs to conform novel 2D materials, and their testing as HTL.

In the present work, SPM techniques are used to characterize three carbo-meric molecules of different symmetries and self-assembled properties. The first of the tested molecules is a dianilin4-yl-carbo-benzene reported as a centrosymmetric (quadrupolar) representative 1 [28]; the second 
is a new dianilin-4-yl-carbo-benzene with dipolar structure whose synthesis is herein documented corresponding to the representative $\mathbf{2}$; the third molecule is a centrosymmetric carbo-quinoid, i.e., 3-dithiol-2-ylidene-carbo-quinoid, recently reported and so-called "carbo-TTF" 3 [29] (see Fig. 1a). STM images of $\mathbf{1}$ and $\mathbf{3}$ show the $2 \mathrm{D}$ arrangement of these $\mathrm{C}_{18}$ ring carbo-mers on a Highly Oriented Pyrolytic Graphite (HOPG) substrate. Electrical/electronic properties of the three carbomers were determined by using AFM and its electrical modes: KPFM and c-AFM. Work function $(\varnothing)$ values measured through KPFM are $\varnothing=5.60 \mathrm{eV}$ for $\mathbf{1}, 4.97 \mathrm{eV}$ for $\mathbf{2}$, and $4.82 \mathrm{eV}$ for $\mathbf{3}$. Hole mobility $(\mu)$ values extracted from local $I-V$ plots by using c-AFM are $15 \times 10^{-8} \mathrm{~cm}^{2} V^{-1} \mathrm{~s}^{-1}$ for $\mathbf{1}, 3 \times 10^{-6} \mathrm{~cm}^{2} V^{-1} \mathrm{~s}^{-1}$ for $\mathbf{2}$, and $87 \times 10^{-8} \mathrm{~cm}^{2} V^{-1} \mathrm{~s}^{-1}$ for $\mathbf{3}$. In addition, the three carbo-mers were implemented (concept tests) for the formation of possible selfassembled hole-transport monolayers (SA-HTL) in OSCs. OSCs were fabricated under the direct configuration: ITO/HTL/PEDOT:PSS/PBDB-T:ITIC/PFN/FM, where PBDB-T is the electrodonor, ITIC is a non-fullerene acceptor, PFN is an alcohol/water soluble conjugated polymer used as electron transport layer (ETL) [30], see Fig. 1a); and FM = Field's metal is an alternative top electrode composed of $\mathrm{Bi}, \mathrm{Sn}$ and In that has been previously reported by our group [30-32]. The best PCE with a HTL of PEDOT:PSS was 5.5\%, whereas with $\mathbf{2}$ as SA-HTM it was 3.9\%. Without a HTL, OSCs showed a PCE of $2.7 \%$. Although PCE values close to $9 \%$ have been achieved in our group under the same configuration (with PEDOT:PSS as HTL) [2, 16], for this current study the maximum PCE was $5.5 \%$ because of the non-optimized procedure followed in [2, 16]; however, the main purpose in these concept tests is just to compare PV performance of OSCs with PEDOT:PSS and carbo-mer SAMs as HTL. These results show that upon optimization, carbomer-based SA-HTLs would be possible alternatives for OSCs.

\section{Experimental}

\subsection{Material and reagents}

Poly[(2,6-(4,8-bis(5-(2-ethylhexyl)thiophen-2-yl)-benzo[1,2-b:4,5-b']dithiophene))-alt-(5,5(1',3'-di-2-thienyl-5',7'-bis(2-ethylhexyl)benzo[1',2'-c:4',5'-c']dithiophene-4,8-dione)] (PBDBT), 3,9-bis(2-methylene-(3-(1,1-dicyanomethylene)-indanone))-5,5,11,11-tetrakis(4hexylphenyl)-dithieno[2,3-d:2',3'-d']-s-indaceno[1,2-b:5,6-b']dithiophene (ITIC) and, the alcohol/water-soluble conjugated polymer poly[(9,9-bis(3'-(N,N-dimethylamino)propyl)-2,7fluorene)-alt-2,7-(9,9-dioctylfluorene)] (PFN), were acquired from 1-Material Inc. The eutectic 
alloy Field's metal (FM, 32.5\% Bi, 51\% In, 16.5\% Sn) was obtained from Rotometals and ITOcovered glass substrates (10 $\Omega$ /square) from Delta Technologies. 1-Phenyloctane was purchased from Sigma-Aldrich and used without further purification.

Tetrahydrofuran (THF), diethyl ether $\left(\mathrm{Et}_{2} \mathrm{O}\right)$, pentane and dichloromethane (DCM) used for the synthesis of the carbo-mers 1, 2, 3 were dried with a PureSolve-MD-5 Innovative Technology system for the purification of solvents. All other reagents were used as commercially available. In particular, the commercial solution of $\mathrm{HCl}$ was $2 \mathrm{M}$ in diethyl ether, and $\mathrm{SnCl}_{2}$ was labelled anhydrous. Silica gel (60 Å, C.C. $70-200 \mu \mathrm{m})$ was used for column chromatography. Silica gel thin layer chromatography (TLC) plates $(60 \mathrm{~F} 254,0.25 \mathrm{~mm})$ were revealed under UV-light and/or by treatment with an ethanolic solution of phosphomolybdic acid $(20 \%)$. The following ${ }^{1} \mathrm{H}$ and ${ }^{13} \mathrm{C}$ NMR spectrometers were used: DPX 300, Avance 500. The ${ }^{1} \mathrm{H}$ and ${ }^{13} \mathrm{C}$ NMR signals were assigned according to chemical shifts, spin-spin coupling constants, splitting patterns, signal intensities; NMR chemical shifts $\delta$ are given in ppm with positive values at high frequency relative to the tetramethylsilane reference. Coupling constants $J$ are in hertz.

\subsection{Synthesis of the carbo-benzene 2}

$\mathbf{2}$ was prepared in two steps from the known [6]pericyclynedione 4 (Scheme 1) [33].

To a solution of $4(0.100 \mathrm{~g}, 0.147 \mathrm{mmol})$ in THF $(10 \mathrm{~mL})$ was added at $0{ }^{\circ} \mathrm{C}$ a solution of Grignard reactant, itself prepared by addition of bromo-bis-trimethylsilylaniline $(0.23 \mathrm{~mL}, 0.88 \mathrm{mmol})$ to $\mathrm{Mg}(0.021 \mathrm{~g}, 0.86 \mathrm{mmol})$ in THF $(1.5 \mathrm{~mL})$ at room temperature. The resulting mixture was stirred $1 \mathrm{~h}$ at $0{ }^{\circ} \mathrm{C}$ and overnight at room temperature, before treatment with water. The aqueous layer was extracted with diethyl ether, and the combined organic layers were washed with brine, separated, dried with $\mathrm{MgSO}_{4}$ and concentrated under reduced pressure. The residue containing the [6]pericyclynediol 5 was directly engaged in the next step without further purification.

To solution of $5(0.147 \mathrm{mmol})$ in DCM $(70 \mathrm{~mL})$ under stirring at $-78^{\circ} \mathrm{C}$ were added successively $\mathrm{SnCl}_{2}(0.283 \mathrm{~g}, 0.149 \mathrm{mmol})$ and $\mathrm{HCl}(1.54 \mathrm{~mL}, 0.3 \mathrm{mmol})$. The resulting mixture was allowed to slowly warm up to $0{ }^{\circ} \mathrm{C}$ before stirring for $1 \mathrm{~h}$ at room temperature. Then an aqueous solution of $\mathrm{NaOH}(1 \mathrm{M}, 3 \mathrm{~mL})$ was added and the stirring was maintained overnight. After washing with brine, the organic layer was separated, dried with $\mathrm{MgSO}_{4}$ and concentrated under reduced pressure. The 
residue was purified by silica gel chromatography (pentane/acetone/THF 8:1:1, then 6:2:2 then THF/acetone 1:1) to give 2 as a violet solid (0.016 g, $15 \%$ from 4$)$.

${ }^{1} \mathrm{H}$ NMR (THF-D 8$) \delta 5.67$ (broad s, 4H), $7.30(\mathrm{~d}, J=7.4 \mathrm{~Hz}, 4 \mathrm{H}), 7.80(\mathrm{~m}, 4 \mathrm{H}), 8.10(\mathrm{~m}, 8 \mathrm{H})$, $9.32(\mathrm{~d}, J=7.4 \mathrm{~Hz}, 4 \mathrm{H}), 9.53-9.60(\mathrm{~m}, 8 \mathrm{H}) .{ }^{13} \mathrm{C}\left\{{ }^{1} \mathrm{H}\right\}$ NMR $\left(\mathrm{THF}-\mathrm{D}_{8}\right) \delta 99.6,11.4,102.6,104.0$, 107.2, 115.1, 115.3, 115.7, 116.5, 117.0, 117.3, 118.6, 128.4, 128.6, 128.8, 129.2, 129.4, 129.5, 129.6, 129.7, 129.9, 132.0, 140.2, 140.4, 140.7. HRMS (MALDI-TOF) $\mathrm{m} / \mathrm{z}$ calculated for $\mathrm{C}_{54} \mathrm{H}_{33} \mathrm{~N}_{2}[\mathrm{M}+\mathrm{H}]^{+}$: 709.2644 , found : 709.2641 .
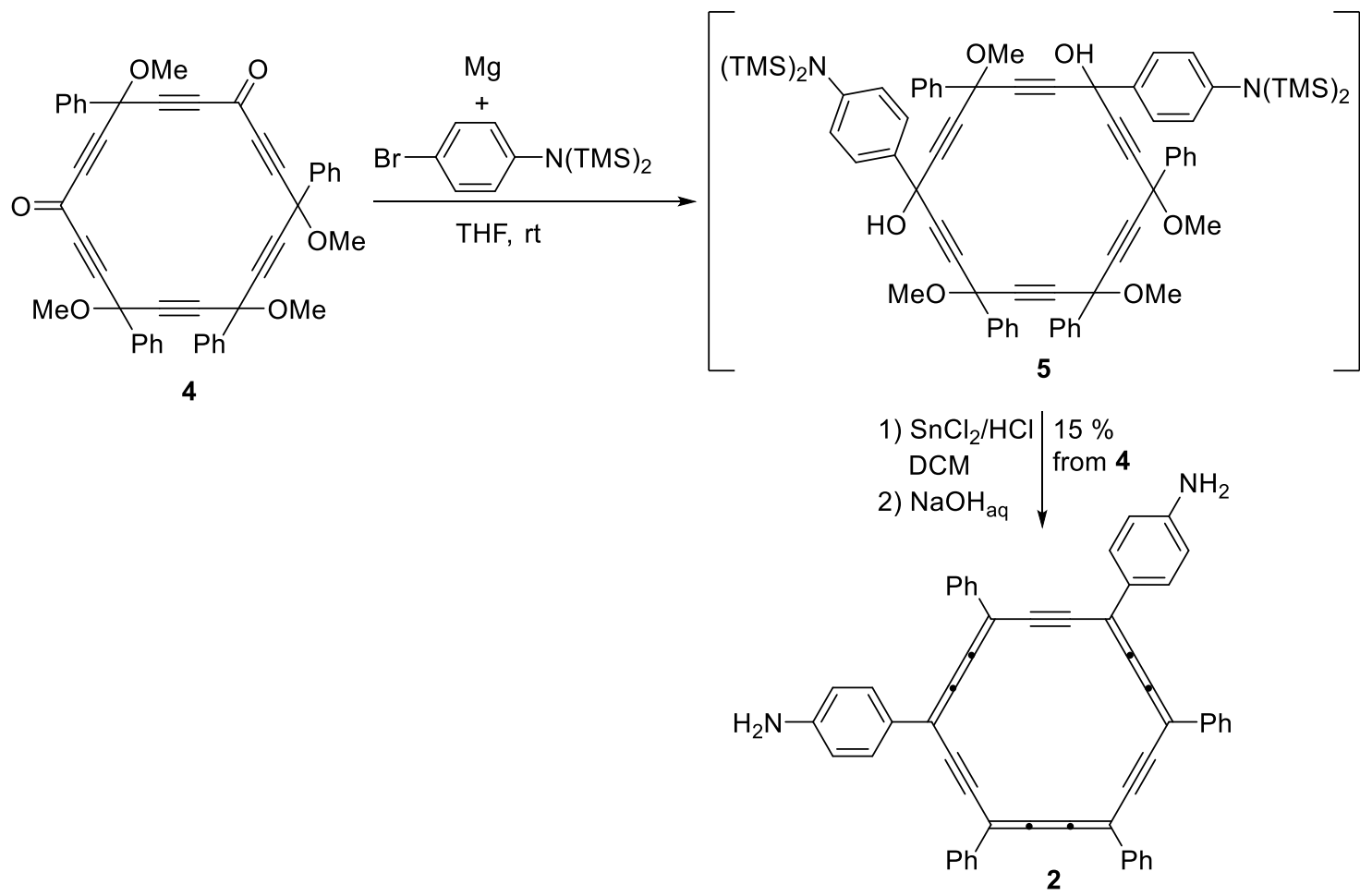

Scheme 1. Synthesis of the dipolar carbo-benzene 2 from the known [6]pericyclynedione 4.

\subsection{Thin films fabrication for SPM measurements}

For STM measurements at the liquid/solid interface [34, 35], carbo-mer samples $(\mathbf{1}, \mathbf{2}$ or $\mathbf{3})$ were dissolved in 1-phenyloctane with a concentration about $0.1 \mathrm{mM}$ and then deposited on HOPG by the drop casting method (thickness $\sim 160$ pm, SAMs). For KPFM and c-AFM determinations, they were dissolved in chlorobenzene with a concentration about $1 \mathrm{mg} / \mathrm{mL}$ and then deposited on ITO surface by drop coating technique (thickness $\sim 10 \mathrm{~nm}$, thin films). 


\subsection{Films characterization}

STM/AFM topographies were obtained with a Nanosurf Easyscan 2 STM/AFM operating at constant current mode. AFM electrical measurements were carried out by using a SmartSPM-1000 AFM from AIST-NT (current noise of $200 \mathrm{fA}$ ). Platinum-coated AFM tips (HQ:NSC15/PT from MikroMasch, PtSi-CONT/NCH and ATEC-CONTPt-SPL from Nanosensors) were used. For KPFM measurement PtSi AFM tips and two-pass mode were used. To calibrate the KPFM system, contact potential difference (CPD) was used where $\varnothing$ of PtSi tip was measured by calibrating it with Highly Oriented Pyrolytic Graphite (HOPG) as reference sample, then ITO reference sample was measured to further check this calibration. Before calibration, HOPG substrate was cleaved by using the adhesive tape technique to achieve an atomically clean surface and, ITO substrate was cleaned sequentially in a soap solution, distilled water, acetone, and isopropanol, in each case for $15 \mathrm{~min}$ in an ultrasonic bath and dried in an oven at $80{ }^{\circ} \mathrm{C}$. The work function for PtSi was $\varnothing$ $=5 \pm 0.13 \mathrm{eV}$, which agrees with previous reports $[37,38]$. Once the PtSi tip and KPFM system were calibrated, measurements were consistence on the multiple samples with a standard deviation of $\pm 0.1 \mathrm{eV}$ under the same measurement conditions. The lift height from the two-pass mode was kept around 15-25 nm and an applied potential of $\pm 4 \mathrm{~V}$. PtSi tip parameters are: force constants $k$ $\approx 0.2 \mathrm{~N} / \mathrm{m}$ and a resonant frequency of $f \approx 13 \mathrm{kHz}$. Preparation of STM tips and substrates as well

as additional technical information can be found elsewhere $[2,35]$. The tunneling conditions of each STM image are given in the corresponding Figure caption. Images were processed and analyzed with the Gwyddion open-source software (v. 2.49), from which mean plane subtraction, Gaussian filter, autocorrelation function (ACF), fast Fourier transform (FFT) and measured distance were determined.

\subsection{OSCs fabrication and characterization}

The ITO-covered glass substrates were cut $(\sim 1.8 \mathrm{~cm} \times 1.8 \mathrm{~cm})$ and ultrasonically cleaned consecutively for $20 \mathrm{~min}$ in a detergent solution, distilled water, and isopropanol, and dried in an oven at $80{ }^{\circ} \mathrm{C}$ for at least $12 \mathrm{~h}$. ITO substrates were treated with oxygen plasma for 20 min before coating. For the HTL, PEDOT:PSS and possible carbo-mer SA-HTLs (from 1, 2 and 3) were tested (see Fig. 1b). A PEDOT:PSS layer of $40 \mathrm{~nm}$ thickness was spin-coated at $4500 \mathrm{rpm}$ for 1 $\min$ on top of the ITO substrate and dried in an oven for $30 \mathrm{~min}$ at $80{ }^{\circ} \mathrm{C}$. Carbo-mers were 
dissolved in 1-phenyloctane (c.a. $0.1 \mathrm{mM}$ ) and kept under stirring for $30 \mathrm{~min}$. ITO substrates were immersed in SAM solutions for $12 \mathrm{~h}$. After that, substrates were rinsed with toluene to remove residual SAM molecules that would not be strongly bonded on the ITO surface. For the active layer, PBDB-T was used as electro-donor and ITIC as electro-acceptor (see Fig. 1a). The solution of the active layer was prepared by dissolving PBDB-T and ITIC at 1:1 w/w, $20 \mathrm{mg} / \mathrm{mL}$ in anhydrous chlorobenzene/1,8-diiodooctane $(99.5: 0.5 \mathrm{v} / \mathrm{v})$ within a glovebox under nitrogen atmosphere. The solution was stirred in a magnetic stir plate for about $24 \mathrm{~h}$ at room temperature. Then, it was spin-coated, at $2500 \mathrm{rpm}$ for $1 \mathrm{~min}$ (active layer thickness $~ 100 \mathrm{~nm}$ ) inside the glovebox, onto the PEDOT:PSS or 1, 2 or 3 monolayer. The active layer was annealed at $160{ }^{\circ} \mathrm{C}$ for $10 \mathrm{~min}$. A PFN layer $(\sim 5-10 \mathrm{~nm})$ was spin-coated at $6000 \mathrm{rpm}$ on top of the active layer and exposed to thermal annealing for 15 minutes at $80{ }^{\circ} \mathrm{C}$. The active area of devices $\left(0.07 \mathrm{~cm}^{2}\right)$ was delimited with a Scotch tape. FM top electrode was deposited by drop casting on top of the PFN layer, after melting it at $95{ }^{\circ} \mathrm{C}$ in a hot plate; during this procedure, the OSC device was kept on the hot plate at the same temperature. Additional details can be found elsewhere [30-32]. Fig. 1a) shows the chemical structure of the studied carbo-meric molecules. In Fig. 1b), the glass/ITO/HTL/PBDB-T:ITIC/PFN/FM OSC architecture used in this work is schematized, where HTL is PEDOT:PSS or carbo-meric SAMs as mentioned above. The OSCs were illuminated with the Air Mass 1.5 spectrum $\left(1000 \mathrm{~W} / \mathrm{m}^{2}\right)$ provided by a solar simulator Sciencetech SS150 class AAA, which was calibrated using a 15151 calibrated reference cell from abet technologies. Current density $v s$ voltage $(J-V)$ curves were acquired by a Keithley 2450 source-meter in ambient conditions. 
a)

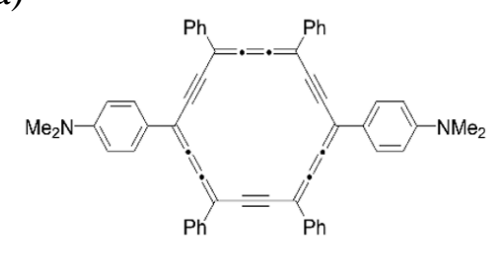

1

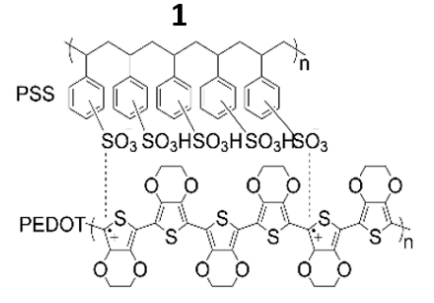

PEDOT:PSS
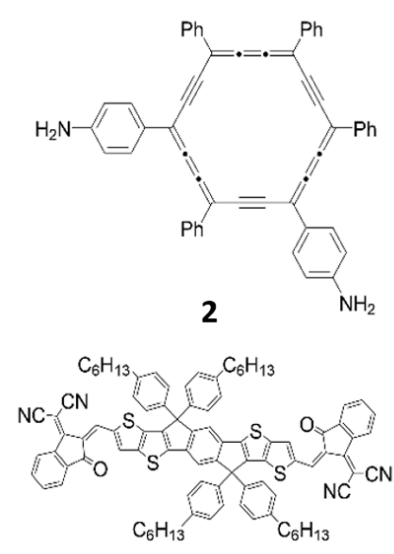

ITIC

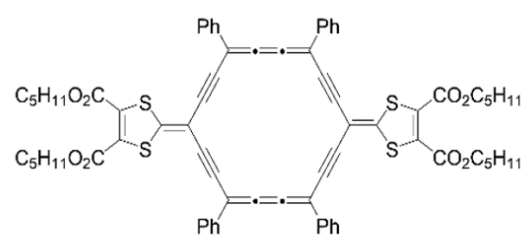

3

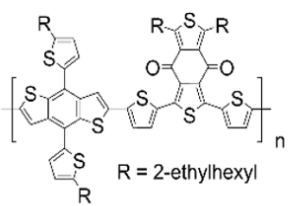

PBDB-T

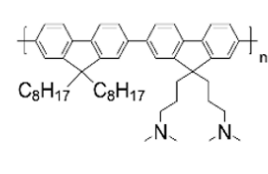

PFN b)

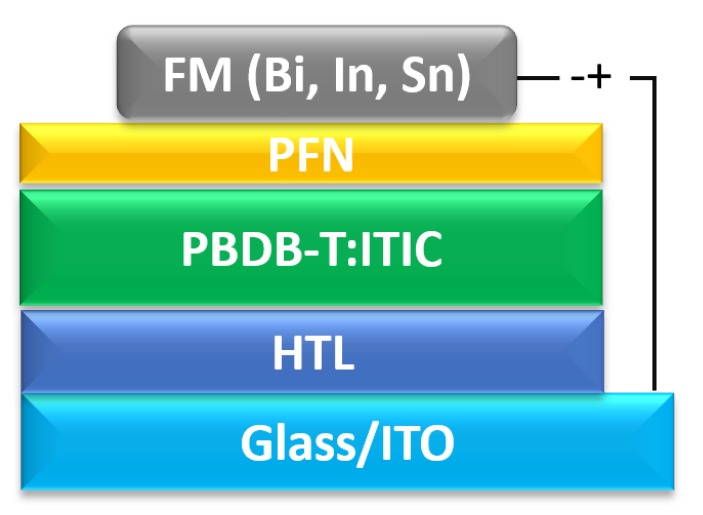

c)

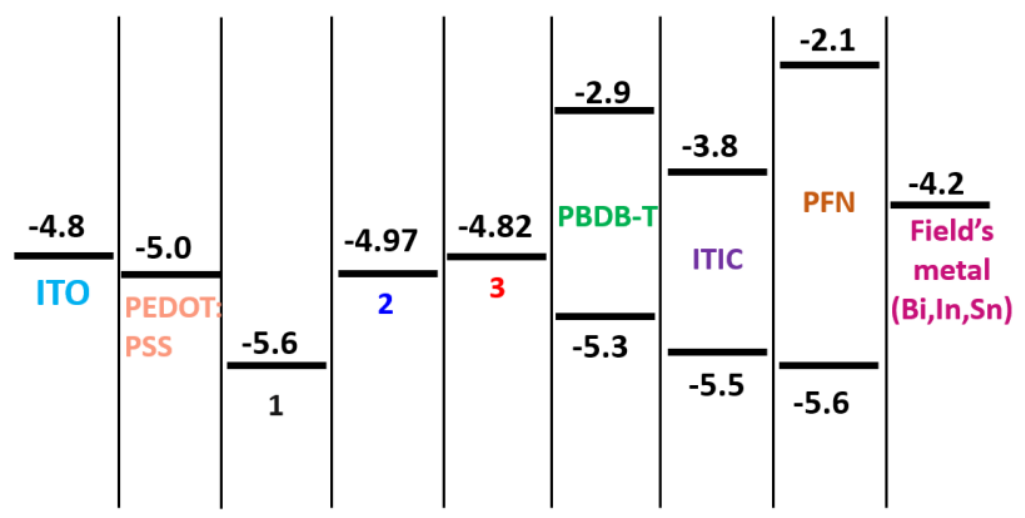

Fig. 1. a) Chemical structures of the compounds used in this work, b) Architecture of the OSC devices. c) Energetic levels of the compounds used in this work (data in eV). Note that our scheme does not intend to represent the absolute values [9-11].

\section{Results and Discussion}

The optical absorption in solution of the carbo-mers 1-3 is displayed in Fig. 2. These spectra present the characteristic features of carbo-benzenes [23]; for instance, the carbo-benzene 1 bearing $\mathrm{NMe}_{2}$ substituents on the phenyl groups in para position of the $\mathrm{C}_{18}$ macrocycle exhibits an intense absorption band at $2.37 \mathrm{eV}(523 \mathrm{~nm})$ and a low-lying energy band of weak intensity at $1.91 \mathrm{eV}(649.1 \mathrm{~nm})$. The carbo-benzene 2 bearing $\mathrm{NH}_{2}$ substituents on the phenyl groups in meta 
positions of the $\mathrm{C}_{18}$ ring has its maximum of absorption at $2.51 \mathrm{eV}(494 \mathrm{~nm})$, shifted by $+0.14 \mathrm{eV}$ with respect to $\mathbf{1}$, characterized as a single main band with a long tail of absorption structured with two shoulders (2.04 and $2.28 \mathrm{eV}$ ). Finally, the carbo-quinoid $\mathbf{3}$ has two intense bands in the red and blue regions of the spectrum at $1.96 \mathrm{eV}(632.5 \mathrm{~nm})$ and $2.78 \mathrm{eV}(446 \mathrm{~nm})$, respectively, resembling the characteristics of the dichromic carbo-cyclohexadiene [23]. The inset in Fig. 2 shows the Tauc plots from which optical bandgap energies $E_{\mathrm{g}}$ of $1.82,2.13$ and $1.86 \mathrm{eV}$ are calculated for 1, 2 and 3, respectively. Here the optical bandgap is interpreted as the onset of optical absorption that produces excitons. The value of $E_{\mathrm{g}}$ in $\mathbf{2}$ is due to a combined effect of the substituents on the phenyl groups in meta or para positions of the carbo-benzene and the strength of the donating groups; the $E_{\mathrm{g}}$ value of the carbo-quinoid $\mathbf{3}$ is similar to the $E_{\mathrm{g}}$ value of $\mathbf{1}$. Notice that the Tauc plot shows additional linear edges for 1, 2 and 3, corresponding to bandgaps of 2.25, 2.33 and $2.64 \mathrm{eV}$, respectively. Two linear edges in Tauc plots are also commonly observed in other organic materials characterized by structured absorption spectra, such as porphyrins [39-41] where the optical gap of lowest energy is the onset of absorption while the one of higher energy is the fundamental energy gap, namely, the energy gap between a combination of the HOMO $\pi$ orbitals and LUMO $\pi^{*}$-orbitals. The energies of $2.25,2.33$ and $2.64 \mathrm{eV}$ are assigned to the fundamental bandgaps of $\mathbf{1 , 2}$ and $\mathbf{3}$. It is thus not surprising then that carbo-benzenes can exhibit various bandgaps as their absorption features (various bands denoting electronic transitions) resemble to some extent the Q and B (Soret) bands displayed by porphyrins. The absorption features of carbo-benzenes were indeed previously explained in terms of the Gouterman fourorbital model originally developed for porphyrins [42]. 


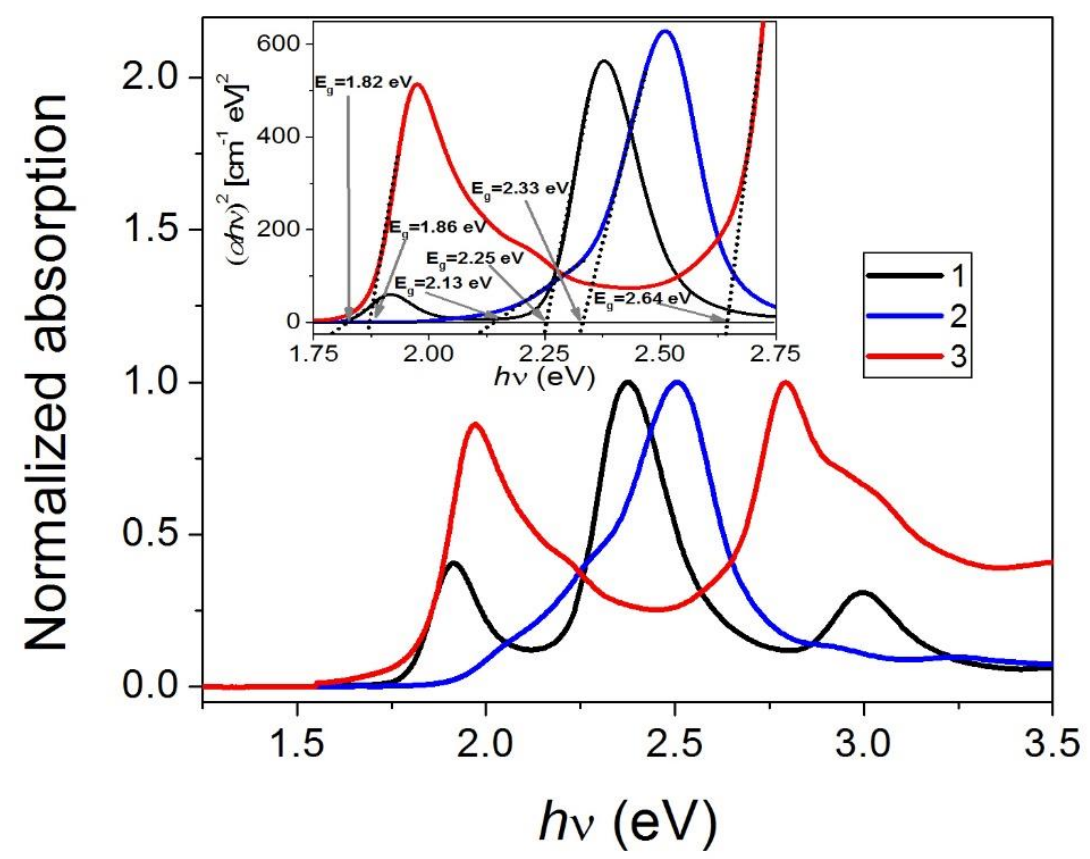

Fig. 2. Absorption spectra of $\mathbf{1}, \mathbf{2}$ and $\mathbf{3}$ in dichloromethane solution. Inset: Tauc plots with dotted lines depicting the linear portion of the spectra from which the optical band-gap $E_{\mathrm{g}}$ is calculated.

Highly ordered self-assembled monolayers of the carbo-benzene $\mathbf{1}$ and carbo-quinoid $\mathbf{3}$ are shown in Figs. 3a)-b). For the carbo-benzene 2, no STM image was observed in 1-phenyloctane at any concentration [43], which does not necessarily mean that a SAM layer is not formed. It has been reported $[44,45]$ that hydrogen bond donors such as carboxylic acid $\left(\mathrm{CO}_{2} \mathrm{H}\right)$ or thiol $(\mathrm{SH})$ groups interact with ITO substrates. The carbo-benzene $\mathbf{2}$ can thus also be anticipated to bind to the ITO by its anilinyl amine groups $\left(\mathrm{NH}_{2}\right)$ [45]. In the case of the carbo-benzene $\mathbf{1}$ and carbo-TTF $\mathbf{3}$, a charge transfer interaction with the surface oxide $\left(\mathrm{ITO}^{\delta \cdots} \mathbf{1}^{\delta+}{ }^{\delta+}\right.$ ) can be invoked to be facilitated by weak oxidation potentials through (quasi)reversible processes $\left(E_{1 / 2}(\mathbf{1})=+0.51 \mathrm{~V}\right.$ vs SCE, $E_{\mathrm{p} / 1 / 2}(3)=+0.18 \mathrm{~V} v s \mathrm{Fc} / \mathrm{Fc}^{+}$, in dichloromethane solution) [28, 29]. Besides, the formation of regular monolayers is expected from the tendency of the macrocyclic cores to stack face-to-face by $\pi-\pi$ interactions when titled at surfaces [26, 29]. STM images of 1 and previously described images of 3 [29] (Figs. 3a)-b)) show ordered monolayers along two horizontal (in-plane) 
orientations. The polarity of the electron-donating dimethylanilinyl groups of $\mathbf{1}$ plays a key role in the molecular orientation on the substrate, because it leads to a complex combination of forces (attractive and repulsive, short- and long-range) that allows the control of assembly dimensionality on the surface with a dipole moment along the molecular axis [46]. Indeed, all atoms are arranged in such a way that the unit-cell axes of the packing arrangement remain unchanged within the domain itself. Benneckendorf et al. [47] reported the structure-property relationships of dipolar phenyl and biphenylphosphonic acid: the strengths of the dipoles are varied through the inclusion of electron-withdrawing fluorine atoms and the molecular length, however, the surface energy is kept constant through the electron-donating $N, N$-dimethylamine fragment, which were able to form self-assembled monolayers on indium-tin oxide (ITO) electrodes modifying its work function $(\varnothing)$. In addition, quantum mechanical calculations showed that the dipole vector of $N, N$ dimethylaniline derivatives is orientated towards the electrode interface, directly influencing changes of the $\emptyset$ value [47]. Meanwhile, by removing the methyl groups from the amino fragment, from $\mathrm{NMe}_{2}$ in $\mathbf{1}$ (quadrupolar) to $\mathrm{NH}_{2}$ in $\mathbf{2}$ (dipolar), the work function of the metal surfaces has been modified by the adsorption of SAMs, which form surface dipoles [48], as observed for 1 but also for the dithiolylidene-substituted carbo-quinoid 3. The ACF (from the Gwyddion software), exposes the lattice vectors of the self-assembly and the separation distance between neighboring molecules (see Figs. 3c)-d)). Characteristic lattice vector data, through STM, are summarized in Table 1. 
a)

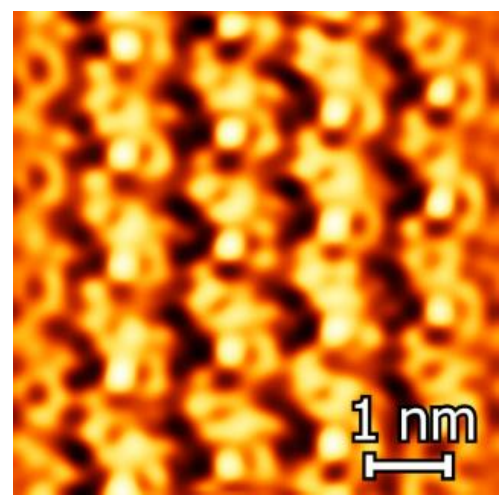

c)

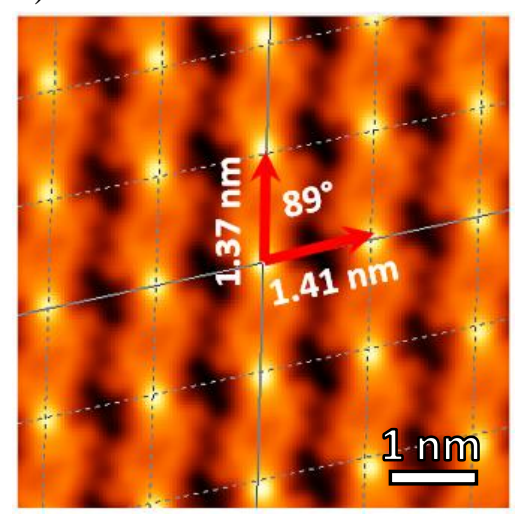

b)

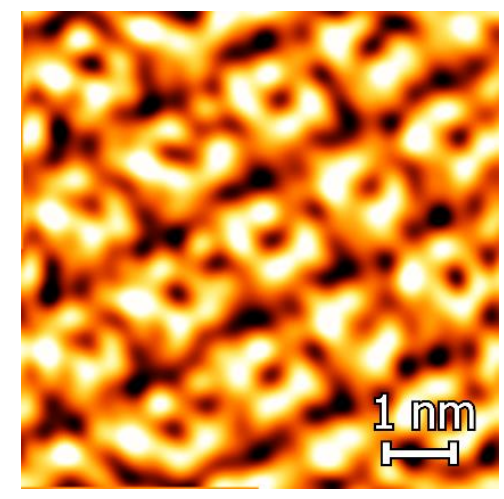

d)

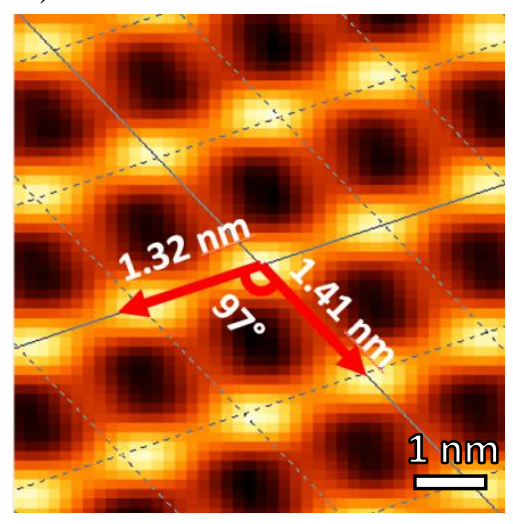

Fig. 3. SAMs of a) 1, tunneling condition; $I t=160 \mathrm{pA}, \mathrm{U}=0.90 \mathrm{~V}$, b) 3, tunneling condition; $I t$ $=140 \mathrm{pA}, U=1.05 \mathrm{~V}$. Lattice parameters by using ACF of c) $\mathbf{1}, \mathrm{d}) \mathbf{3}$.

Table 1. Lattice parameters of SAMs of the carbo-benzene $\mathbf{1}$ and carbo-quinoid $\mathbf{3}$ on HOPG (STM determinations).

\begin{tabular}{cccc}
\hline Carbo-mer & $a(\mathrm{~nm})$ & $b(\mathrm{~nm})$ & $\alpha\left(^{\circ}\right)$ \\
\hline $\mathbf{1}$ & 1.41 & 1.37 & 89 \\
$\mathbf{2}$ & - & - & - \\
$\mathbf{3}$ & 1.32 & 1.41 & 97 \\
\hline
\end{tabular}

As previously reported [29], STM topography of the carbo-quinoid 3 exposes extended layers of self-assembled molecules with an average thickness of $\sim 160 \mathrm{pm}$. In the case of the carbo-benzene 
1, a large scale STM image (Fig. 4a) reveals a columnar arrangement. However, high resolution STM image (Fig. 4b) shows that the macrocycles are twisted out of the molecular plane, which may be attributed to rotation of the already twisted C-N bonds induced by repulsion between the lone-pair electrons at the nitrogen and the substrate (see blue arrows in Fig. 4b) [49], where the bright points can be assigned to the dimethylanilinyl groups. Fig. 4c) shows a schematic drawing of the self-assembly of the blue arrows zones in Fig. 4b).

a)

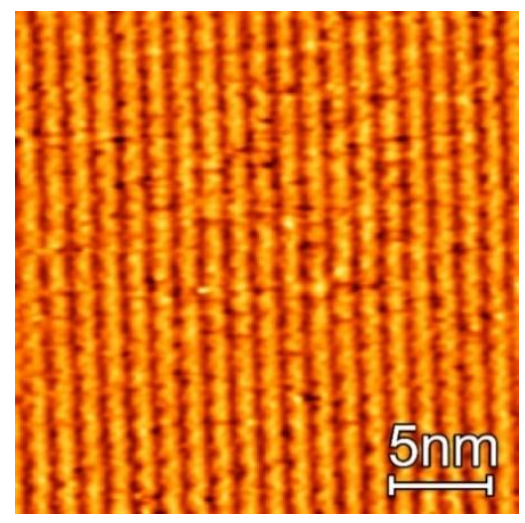

c)

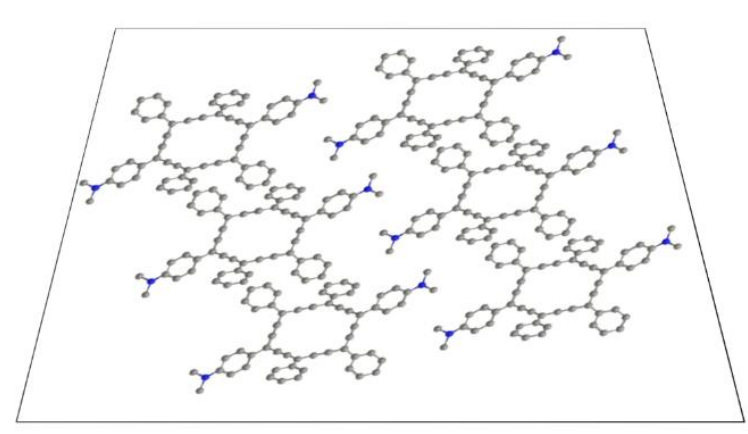

b)

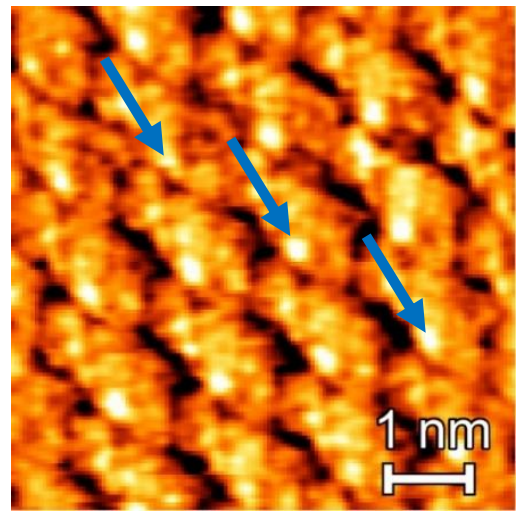

d)

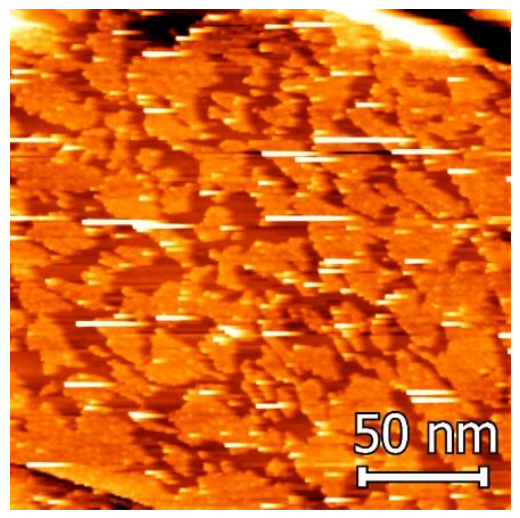

Fig. 4. a) STM image of a self-assembled film of the carbo-benzene $1(I t=140 \mathrm{pA}, U=1.05 \mathrm{~V})$, b) High resolution image ( $I t=160 \mathrm{pA}, U=0.90 \mathrm{~V})$, c) Schematic arrangement of assembled molecules of $\mathbf{1}$ (where the blue arrows in b) indicate), d) Large-scale STM images showing the clusters formed by the carbo-benzene 1 (horizontal stripes are noise due to unsteady feedback loop -tip oscillation- at large scale scanning). 
As suggested by the STM images, the organization of the molecules on the substrate to form SAMs is governed by weak intermolecular interactions between the $\pi$-electron-rich, planar and moderately rigid carbo-aromatic $\mathrm{C}_{18}$ cores [21], depending on both their substitution pattern (dipolar or quadrupolar) and the nature of their substituents: the molecules are anchored to the substrate but their mean planes are not parallel to its surface, titling and overlapping with neighbors by $\pi$ - $\pi$ stacking. These $\pi$-stacking interactions are however likely too weak by themselves to allow the formation of stable multilayers on the ITO without assistance of hydrogen bond donor or acceptor. Indeed, $\pi-\pi$ stacking between carbo-benzene rings are quite rare, even in the crystal state, with only partial parallel overlap of $\mathrm{C}_{18}$ hexagons, e.g. by $25 \%$ only in titled $\mathrm{C}_{18}-\mathrm{C}_{18}$ columnar arrangements of carbo-benzene hydrocarbons [26, 50].

For imaging the electrical properties of thin layers of carbo-mers, films with a thickness of $\sim 10$ nm were deposited on ITO substrates. Figs. 5 a)-c) correspond to a Root Mean Square (RMS) roughness $\left(R_{\mathrm{q}}\right)$ analysis resulting in the values: $R_{\mathrm{q}}=12 \mathrm{~nm}$ for $1, R_{\mathrm{q}}=18 \mathrm{~nm}$ for 2 and $R_{\mathrm{q}}=8 \mathrm{~nm}$ for 3; these relatively high roughness values are due to the low solubility of the studied carbomers, preventing the preparation of highly regular and smooth thin solid films by drop casting or spin casting techniques. Such a lack of solubility of carbo-benzene derivatives is a general issue that was shown to prevent their study for organic photovoltaic applications - as either donor or acceptor components in the active layer - as mentioned in previous reports [51, 52].

KPFM is an electrical mode of AFM, which can visualize the changes in the internal potential distribution between the tip and the surface, commonly referred to as the contact potential difference (CPD) [2, 53]. KPFM is one of the most sensitive techniques for $\varnothing$ measurement, determined from surface contact potential differences $\left(V_{\mathrm{CPD}}\right)$ between the conductive tip and the sample [54]. Figs. 5 d)-f) show the potential distribution on the surface of films of carbo-mers on ITO measured through KPFM. Here, the use of uniform PtSi-coated tips avoid topography correlated artifacts (topography inhomogeneities induced by electrostatic forces through the contact of the tip with the sample) [55] and the contact potential difference gives $\varnothing$ value of 5.60 $\mathrm{eV}$ for $\mathbf{1}, 4.97 \mathrm{eV}$ for $\mathbf{2}, 4.82 \mathrm{eV}$ for 3. 
a)

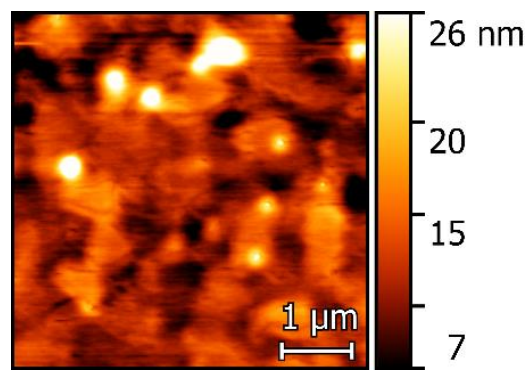

d)

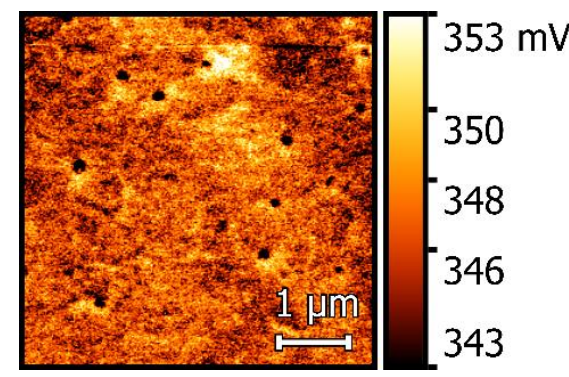

b) $\quad 2$

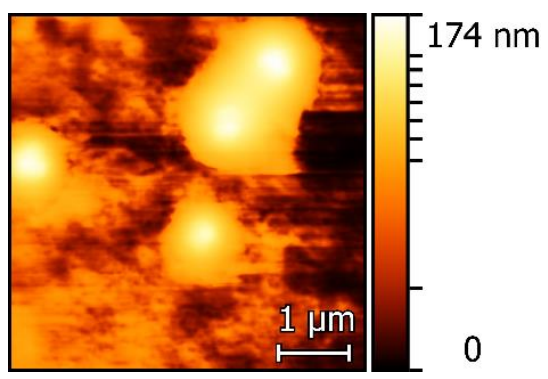

e)

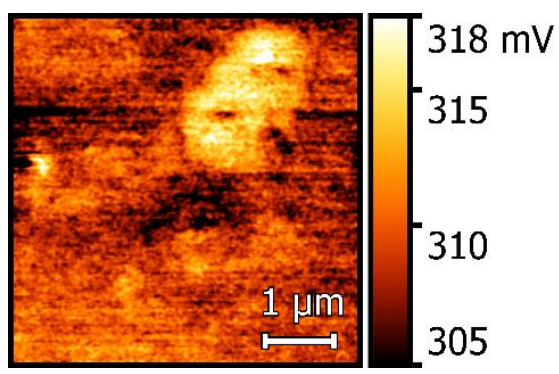

c)

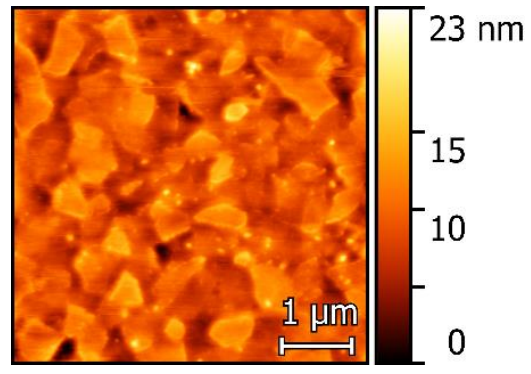

f)

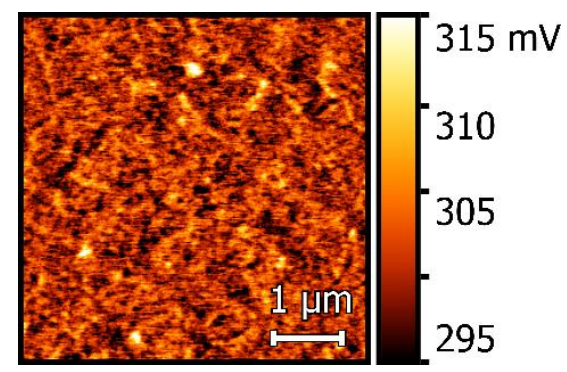

Fig. 5. AFM measurements on thin layers $(T=\sim 10 \mathrm{~nm})$ of the $\mathrm{C}_{18}$ ring carbo-mers $\mathbf{1}, \mathbf{2}$ and 3. a), b), c): topography using contact mode AFM; d), e), f): contact potential difference using KPFM.

Fig. 6 displays local $I-V$ curves (linear and root square plots) for the three carbo-mer thin films, where each curve being the average of 4 measurements resulting in a relative standard deviation of the mean from $10 \%-17 \%$ due to the roughness in each film [56]. From these local $I-V$ curves (Fig. 6b), hole mobility ( $\mu$ ) was extracted by using a modified space-charge limited current (eq. 1) (SCLC) model that accounts for the AFM tip-sample geometry [56, 57]; additional details of the used parameters for the quantitative interpretation can be found elsewhere [2, 56, 57].

$$
J=8.2 \varepsilon_{o} \varepsilon_{r} \mu \frac{V^{2}}{T^{3}} \delta\left(\frac{T}{d}\right)^{1.6 \pm 0.1}
$$

where $\varepsilon_{o}$ and $\varepsilon_{r}$ are the vacuum dielectric permittivity constant and the thin film dielectric constant (relative electrical permittivity), respectively; for organic semiconductors it was assumed $\varepsilon_{r}=3$ [57], $\mu$ is the charge carrier mobility, $T$ is the thickness of the semiconductor thin film and $d$ is the tip-contact radius. For the contact radius $d$, the tip-substrate contact area was estimated from DMT model [56] (for PtSi probes the contact radius $d$ is $5.8 \mathrm{~nm}$ ). The constant 8.2 is the prefactor determined from the finite element modeling to account for the nonuniform electrical field [57]. 
The constant $\delta=7.8 \pm 1$ was included to empirically account for the difference between mobilities derived from c-AFM measurements and those from planar electrodes. Average local film thickness is determined by tapping mode AFM, where topographic height (roughness) at each sample location is measured together with the film thickness. However, the accuracy of thickness measurement of thin films is limited when the surface is enough rough [58]. Therefore, the hole mobility is thickness dependence ( $J \propto T^{-1.4 \pm 0.1}$ ) when carrying out the experiment using c-AFM, as well as dependence in the tip diameter (geometry) and current fluctuations due to film roughness. The above-mentioned dependencies lead that to the estimated hole mobility of sample $\mathbf{3}$ be larger than that of sample $\mathbf{1}$ even though slope in Fig. $6 \mathrm{~b}$ is larger for $\mathbf{1}$ (see Table 2).

The $I-V$ curves (Fig. 6a) show a non-ohmic or " $S$ " shape behavior, suggesting that charge transport occurs through a tunnel potential barrier, although the responses are different in the three thin films [48] (3 exhibits a wider and flat curve - built-in potential from the y-intercept- than $\mathbf{1}$ and 2 ): higher current is observed when the slope is greater [59]. The estimated hole mobility values are $15 \times 10^{-8} \mathrm{~cm}^{2} V^{-1} \mathrm{~s}^{-1}$ for $\mathbf{1}, 3 \times 10^{-6} \mathrm{~cm}^{2} V^{-1} \mathrm{~s}^{-1}$ for 2 and $87 \times 10^{-8} \mathrm{~cm}^{2} V^{-1} \mathrm{~s}^{-1}$ for 3 . These values are lower than mobility of PEDOT:PSS, which is in the range of $3 \times 10^{-4}-5 \times 10^{-5} \mathrm{~cm}^{2} \mathrm{~V}^{-1} \mathrm{~s}^{-1}$ $[60,61]$. Table 2 summarizes the morphology, electrical and electronic properties of the three carbo-mers.

a)

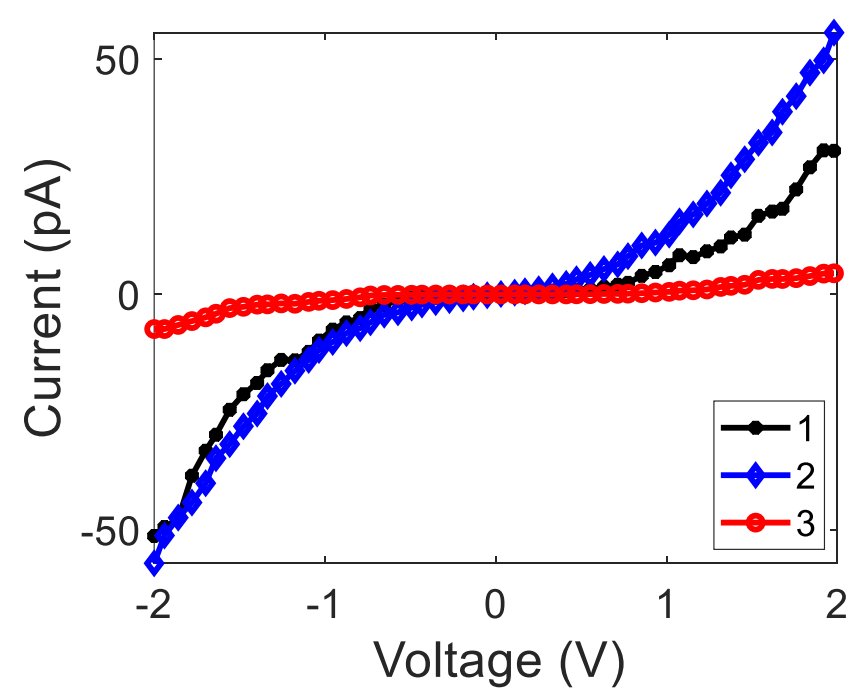

b)

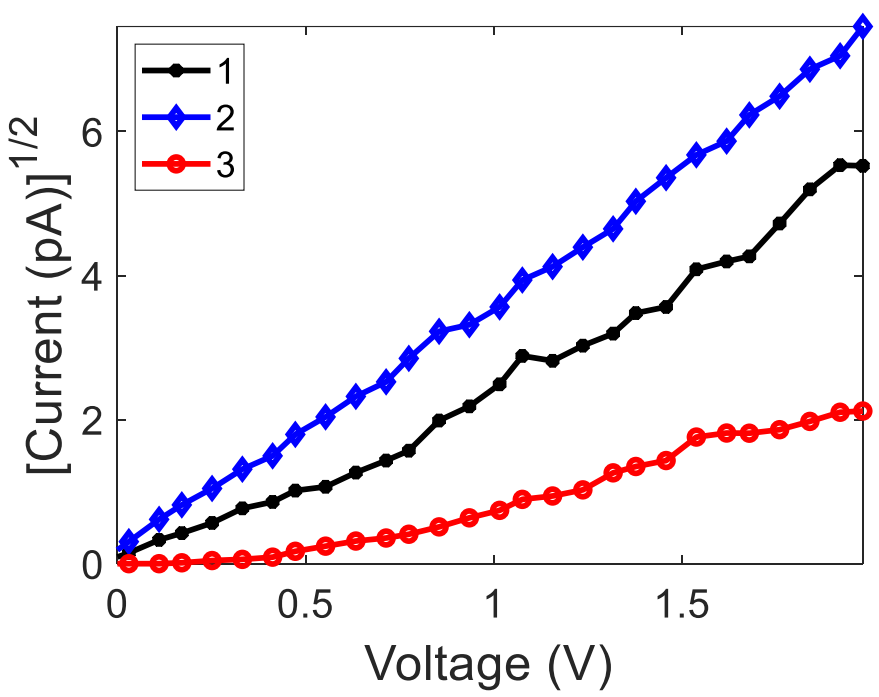


Fig. 6. Local $I-V$ plots acquired by c-AFM, for thin films $(\sim 10 \mathrm{~nm})$ of the $\mathrm{C}_{18}$ ring carbo-mers $\mathbf{1}$, $\mathbf{2}, \mathbf{3}$, a) Linear scale, b) $I^{1 / 2}-V$ plot.

Table 2. Morphology, electrical and electronic properties of thin films of the $\mathrm{C}_{18}$ ring carbo-mers

$\mathbf{1 , 2}, \mathbf{3}$, using chlorobenzene as solvent, for thin films of $c a 10 \mathrm{~nm}$ thickness (PEDOT:PSS parameters are also shown for comparison purposes).

\begin{tabular}{cccccc}
\hline Carbo-mer & $\begin{array}{c}\text { Roughness } \\
(\mathrm{nm})\end{array}$ & $\begin{array}{c}\text { Work function }(\emptyset) \\
(\mathrm{KPFM})(\mathrm{eV})\end{array}$ & $\begin{array}{c}\text { Hole mobility }(\mu) \\
(\mathrm{c}-\mathrm{AFM}) \\
\left(\mathrm{cm}^{2} \mathrm{~V}^{-1} \mathrm{~s}^{-1}\right)\end{array}$ & $\begin{array}{c}\text { Optical } \\
\text { Bandgap } \\
(\mathrm{eV})\end{array}$ & Reference \\
\hline $\mathbf{1}$ & 12 & 5.60 & $15 \times 10^{-8}$ & 1.82 & This work \\
$\mathbf{2}$ & 18 & 4.97 & $3 \times 10^{-6}$ & 2.13 & This work \\
$\mathbf{3}$ & 8 & 4.82 & $87 \times 10^{-8}$ & 1.86 & This work \\
PEDOT:PSS & 2 & $5.0^{\mathrm{a}}$ & $3 \times 10^{-4}-5 \times 10^{-5}$ a & $2-2.2$ & {$[60,61]$} \\
\hline
\end{tabular}

${ }^{a}$ WF for PEDOT:PSS was determined by KPFM and hole mobility through space-charge-limited current (SCLC) technique with the hole-only devices fabricated.

The use of SAMs of carbo-mers as HTLs could offer the benefits of uniform layers of minimal thickness ( 160 pm). Fig. 7 shows preliminary results with the $C_{18}$ ring carbo-mers $\mathbf{1}, \mathbf{2}$ or $\mathbf{3}$ as SA-HTL in OSCs. As can be seen from Fig. 7 and Table 3, with these SA-HTLs, OSCs show lower efficiency than by using PEDOT:PSS as HTL, probably because the low concentration of carbo-mer solutions at $0.1 \mathrm{mM}$ in 1-phenyloctane (Fig. 3a) did not allow a full homogeneous coverage of the ITO substrate by the SAMs, resulting in low ohmic contact with the active layer [16]. For this reason, the preparation of the SAMs needs to be optimized to improve the efficiency of related carbo-mers in OSCs. Optimization of concentration, solvent (or mixtures of solvents) and drying time could allow obtaining a uniform monolayer homogeneously covering the ITO surface, and thus possibly reaching higher efficiencies. However, these $J-V$ plots, as test of concept, evidence the possibility to use carbo-mers as SAMs for replacing PEDOT:PSS as HTL. The best PV performance was determined with a SAM based on 2, perhaps because of its larger 
hole mobility value (see Table 2) than that measured for thin films of $\mathbf{1}$ and $\mathbf{3}$. The low mobility of carbo-mers prevents efficient charge extraction in OSCs, which need a hole mobility ca $10^{-3} \mathrm{~cm}^{2} V^{-1} \mathrm{~s}^{-1}[60,61]$. Another factor that can affect this PV behavior is the estimated $\emptyset$ value of $4.93 \mathrm{eV}$ for $\mathbf{2}$, which is lower than that for 1: $5.60 \mathrm{eV}$ (however, slightly higher than that for 3: $4.82 \mathrm{eV}$ ), and its matching with that of ITO: $4.8 \mathrm{eV}$. Since a higher $\varnothing$ value than that of ITO will provide a barrier to hole extraction, it is desire that $\varnothing$ is close to the active layer's highest occupied molecular orbital (HOMO) level (PBDB-T; $5.3 \mathrm{eV})$ [62], and then hole injection from the active layer to the anode is facilitated. The above-indicated HOMO levels and $\emptyset$ values reflect the relative positions of the transport energy levels (absolute values). Furthermore, according to Fig. 2 and Tauc plot, the largest $E_{\mathrm{g}}$ value of the three carbo-mers is precisely that of 2: $2.13 \mathrm{eV}$. The wide $E_{\mathrm{g}}$ for 2 and its $\varnothing$ value could better allow to block electrons, thus preventing large energy loss resulting from a band offset between the HOMO level of PBDB-T (5.21 eV) and the SAM [63]. Nevertheless, these PCE values are still lower than those reported when PEDOT:PSS is used as HTL mainly because the well optimized parameters of PEDOT:PSS (see Table 2), thus requiring future optimization of both the preparation of the SAMs and possibly to the structure of carbomers. However, due the well-known hydrophilic and acidic nature of PEDOT:PSS [13], it is expected that its replacement by more hydrophobic components would be a first step to improve the device stabilization. Several materials have been previously reported as alternative to PEDOT:PSS to improve stability and in some cases to achieve a higher PCE value, such as SAMs $[8,17,18]$ and layers of graphene derivatives [11]. While such $\mathrm{sp}^{2}$-carbon-rich aromatic materials thus tend to repel water molecules from the device, the effect is expected to be at least similar for the present $\mathrm{sp}$-/ $\mathrm{sp}^{2}$-carbon-rich carbo-aromatic molecules [21]. It is also noteworthy that a carbobenzene bearing ethynylanilinyl substituents was recently shown to form a stable hydrophobic layer on another metallic oxide $\left(\mathrm{TiO}_{2}\right)$ covered with silver nanoparticles $(\mathrm{Ag})$ and to stabilize these two components in water suspensions, that are a priori oxidizing (as being used for photocatalytic water splitting: $2 \mathrm{H}_{2} \mathrm{O} \rightarrow 2 \mathrm{H}_{2}+\mathrm{O}_{2}$ ), over long periods [24, 64]. Furthermore, the ability to form monolayers makes carbo-mers promising candidates for reducing manufacturing costs since their extremely low material consumption. 


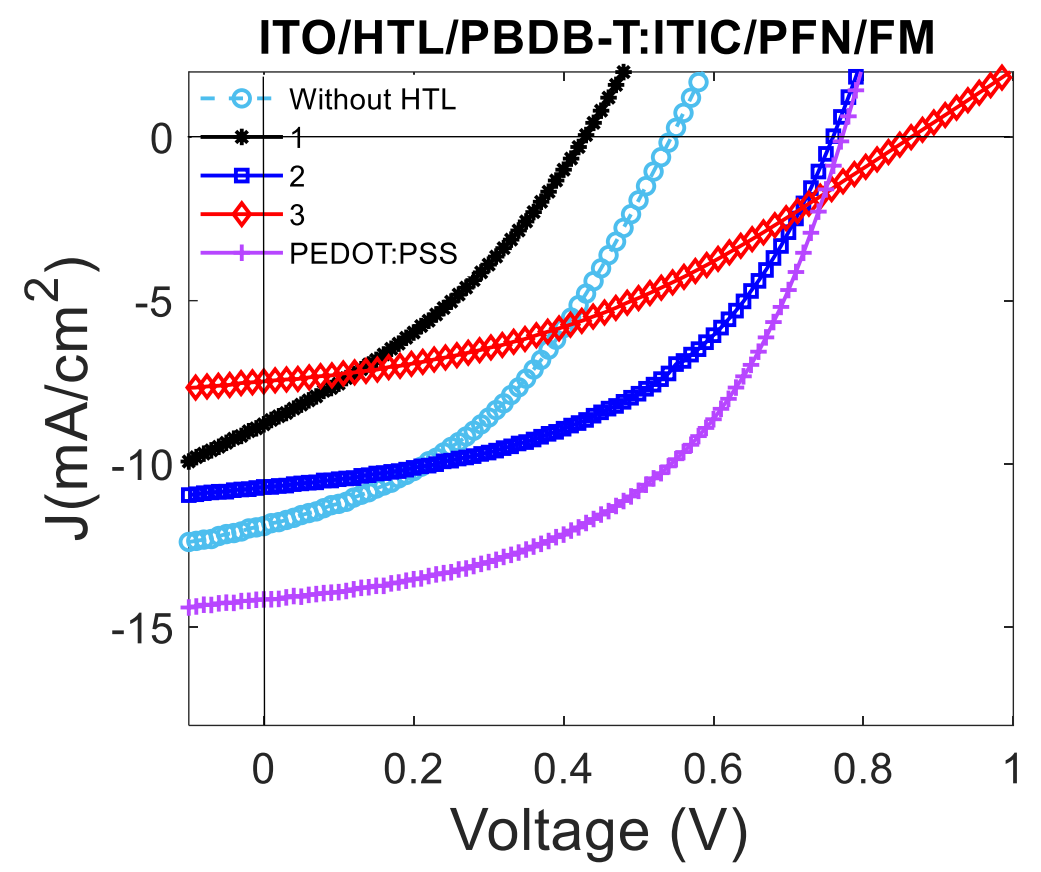

Fig. 7. $J$ - $V$ curve for PBDB-T:ITIC based OSC devices using the FM alternative top electrode vacuum-free deposited, with a HTL made of the $\mathrm{C}_{18}$ ring carbo-mer $\mathbf{1}, \mathbf{2}$ or $\mathbf{3}$.

Table 3. PV parameters of OSCs with a HTL of the $\mathrm{C}_{18}$ ring carbo-mer $\mathbf{1}, \mathbf{2}$ or $\mathbf{3}$. Most promising result for the dipolar carbo-benzene 2.

\begin{tabular}{ccccc}
\hline $\begin{array}{c}\text { Configuration: } \\
\text { Glass/ITO/HTL/PBDB-T:ITIC/PFN/FM }\end{array}$ & $V_{O C}(V)$ & $J_{s c}\left(\mathrm{~mA} / \mathrm{cm}^{2}\right)$ & FF & $\begin{array}{c}\text { PCE } \\
(\%)\end{array}$ \\
\hline Without HTL & 0.55 & 12.1 & 0.41 & 2.7 \\
$\mathbf{1}$ & 0.44 & 9.0 & 0.33 & 1.3 \\
$\mathbf{2}$ & 0.76 & 10.7 & 0.48 & 3.9 \\
$\mathbf{3}$ & 0.86 & 7.5 & 0.38 & 2.5 \\
PEDOT:PSS & 0.77 & 14.2 & 0.50 & 5.5 \\
\hline
\end{tabular}

Regarding previous reports on the use of SAMs as HTL in solar cells, Magomedov et al. [65], used a phosphonic acid-substituted carbazole derivative as hole transporting SAM allowing to 
reach a PCE over $16 \%$ in regular configuration (PiN) perovskite-based solar cells (PSCs). Meanwhile. Yalcin et al. [17] reported a SAM of polyaromatic molecules functionalized with a carboxylic acid group leading to a PCE of $17.3 \%$, which is among the highest efficiency reported to date for PiN PSCs by using an alternative HTL. Zhong et al. [66] observed a slight enhancement of the photovoltaic performance from 3.18\% (with PEDOT:PSS) to $3.20 \%$ in OSCs having an ITO/HTL/CuI/P3HT:PC ${ }_{61} \mathrm{BM} / \mathrm{ZnO} / \mathrm{Al}$ configuration with a SAM of 3-aminopropanoic acid as HTL. Very recently, Lin et al. [8] reached a PCE value of 18.03\% upon using a SAM based on [2(9H-carbazol-9-yl)ethyl]phosphonic acid (2PACz) along with a ternary active layer based on the very efficient PM6 donor. Most of the reported SAMs used as HTL are made of molecules bearing functional anchoring groups that interact with the metal oxide surface, and can influence the structure or thin film morphology and thus a suited conformation and contact of the deposited active layer [67].

\section{Conclusions}

In this work, self-assembled and conductive properties of 2D nano-films prepared from two carbobenzenes and one carbo-quinoid were studied by SPM. STM images of the quadrupolar carbobenzene 1 show that the molecular orientation could be controlled by the polarity of dimethylanilinyl group influencing the dimensionality of assemblies on the surface, although no satisfactory STM images were obtained for the dipolar demethylated counterpart 2. The STM images for the quadrupolar carbo-quinoid 3, previously reported by our group, were related with those for 1. Work function measured through KPFM resulted in values of $\varnothing=5.60 \mathrm{eV}$ for $\mathbf{1}, 4.97$ $\mathrm{eV}$ for $\mathbf{2}$, and $4.82 \mathrm{eV}$ for $\mathbf{3}$. Hole mobility $(\mu)$ values extracted from local I-V plots by using cAFM were $15 \times 10^{-8} \mathrm{~cm}^{2} V^{-1} s^{-1}$ for $\mathbf{1}, 3 \times 10^{-6} \mathrm{~cm}^{2} V^{-1} \mathrm{~s}^{-1}$ for $\mathbf{2}$, and $87 \times 10^{-8} \mathrm{~cm}^{2} V^{-1} \mathrm{~s}^{-1}$ for 3 . The high roughness $(8-18 \mathrm{~nm})$ and low homogeneity of thin films based on the selected carbo-mer derivatives, make them poorly adapted for use in the active layer of OSCs. Nevertheless, their ability to form SAMs, make them attractive for a possible use as alternative 2D HTL in OSCs, ensuring contact selectivity between the anode and the active layer. The highest PCE with a HTL of PEDOT:PSS was 5.5\%, whereas a non-fully optimized value of 3.9\% was obtained with a SAHTM of the carbo-benzene 2. Such $\mathrm{C}_{18}$ ring carbo-mers could thus offer an alternative to conventional compounds used in the HTL, with the view to increasing the stability of OSCs. 
Further improvements of both the carbo-mer structure by changing the nature and position of the substituents at the (pro)aromatic $\mathrm{C}_{18}$ ring, and the preparation of the SAMs, should allow reaching higher OSC performance. Efforts will thus be pursued in this direction.

\section{Acknowledgements}

Centre National de la Recherche Scientifique (CNRS) is acknowledged for funding. The authors thank the French-Mexican International Associated Laboratory (LIA) "Molecular Chemistry with Applications in Materials and Catalysis" funded by the CNRS and the CONACyT, and the ECOS Nord program M16P02 “Carbo-meric Chromophores for Two-Photon Absorption”, 2017-2020, and the CONACyT grant \# 291434 “Absorción óptica no lineal en nuevos materiales orgánicos: el caso de cromóforos carbomeros" 2017-2021 for binational France-Mexico scientific collaboration. Authors also thank CONACyT grant "Laboratorio Nacional de Materiales Grafénicos (LNMG)". I. C.-Q. thanks CONACyT for the granted scholarship. J. R.-T. thanks "Universidad Nacional de San Agustín de Arequipa (UNSA), Perú” for financial support through the grant \# TD-004-2018-UNSA. Authors also thank to M. Olmos from GPOM-CIO (Mexico) for his technical assistance and M. Tassé from LCC-CNRS Toulouse (France) for AFM assistance. Thanks are due to Prof. Mogens Brøndsted Nielsen, University of Copenhagen, who has long inspired the design and study of the carbo-TTF molecule 3.

\section{Declaration of Competing Interest}

The authors declare that they have no conflict of interest.

\section{References}

[1] A. Deshpande, B.J. LeRoy, Scanning probe microscopy of graphene, Physica E Low Dimens. Syst. Nanostruct. 44 (2012) 743-759. https://doi.org/10.1016/j.physe.2011.11.024

[2] I. Caballero-Quintana, O. Amargos-Reyes, J.L. Maldonado, J. Nicasio-Collazo, D. Romero-Borja, D. Barreiro-Arguelles, G. Molnar, A. Bousseksou, Scanning Probe Microscopy Analysis of Nonfullerene Organic Solar Cells, ACS Appl. Mater. Interfaces 12 (2020) 29520-29527. https://doi.org/10.1021/acsami.0c06048

[3] Q. Ferreira, C.L. Delfino, J. Morgado, L. Alcacer, Bottom-Up Self-Assembled Supramolecular Structures Built by STM at the Solid/Liquid Interface, Materials 12 (2019) 382. https://doi.org/10.3390/ma12030382 
[4] T. Coffey, A. Seredinski, J.N. Poler, C. Patteson, W.H. Watts, K. Baptiste, C. Zheng, J. Cody, C.J. Collison, Nanoscale characterization of squaraine-fullerene-based photovoltaic active layers by atomic force microscopy mechanical and electrical property mapping, Thin Solid Films 669 (2019) 120-132. https://doi.org/10.1016/j.tsf.2018.10.046

[5] J. Lee, J. Kong, Potential Dip in Organic Photovoltaics Probed by Cross-sectional Kelvin Probe Force Microscopy, Nanoscale Res Lett 13 (2018) 228. https://doi.org/10.1186/s11671-018-2639-6

[6] B. Lee, S. Lee, D. Cho, J. Kim, T. Hwang, K.H. Kim, S. Hong, T. Moon, B. Park, Evaluating the Optoelectronic Quality of Hybrid Perovskites by Conductive Atomic Force Microscopy with Noise Spectroscopy, ACS Appl. Mater. Interfaces $8 \quad$ (2016) 30985-30991. https://doi.org/10.1021/acsami.6b11011

[7] Q. Liu, Y. Jiang, K. Jin, J. Qin, J. Xu, W. Li, J. Xiong, J. Liu, Z. Xiao, K. Sun, S. Yang, X. Zhang, L. Ding, $18 \%$ Efficiency organic solar cells, Science Bulletin 65 (2020) 272-275. https://doi.org/10.1016/j.scib.2020.01.001

[8] Y. Lin, Y. Firdaus, F.H. Isikgor, M.I. Nugraha, E. Yengel, G.T. Harrison, R. Hallani, A. El-Labban, H. Faber, C. Ma, X. Zheng, A. Subbiah, C.T. Howells, O.M. Bakr, I. McCulloch, S.D. Wolf, L. Tsetseris, T.D. Anthopoulos, Self-Assembled Monolayer Enables Hole Transport Layer-Free Organic Solar Cells with 18\% Efficiency and Improved Operational Stability, ACS Energy Lett. 5 (2020) 2935-2944. https://doi.org/10.1021/acsenergylett.0c01421

[9] H.-T. Chien, M. Pölzl, G. Koller, S. Challinger, C. Fairbairn, I. Baikie, M. Kratzer, C. Teichert, B. Friedel, Effects of hole-transport layer homogeneity in organic solar cells - A multi-length scale study, Surfaces and Interfaces 6 (2017) 72-80. https://doi.org/10.1016/j.surfin.2016.11.008

[10] Y.-J. Jeon, J.-M. Yun, M. Kang, S. Lee, Y.-S. Jung, K. Hwang, Y.-J. Heo, J.-E. Kim, R. Kang, D.-Y. Kim, 2D/2D vanadyl phosphate (VP) on reduced graphene oxide as a hole transporting layer for efficient organic solar cells, Org. Electron. 59 (2018) 92-98. https://doi.org/10.1016/j.orgel.2018.03.021

[11] J. Nicasio-Collazo, J.-L. Maldonado, J. Salinas-Cruz, D. Barreiro-Argüelles, I. Caballero-Quintana, C. Vázquez-Espinosa, D. Romero-Borja, Functionalized and reduced graphene oxide as hole transport layer and for use in ternary organic solar cell, Opt. Mater. 98 (2019) 15. https://doi.org/10.1016/j.optmat.2019.109434

[12] X. Huang, H. Yu, Z. Wu, Y. Li, Improving the performance of polymer solar cells by efficient optimizing the hole transport layer-graphene oxide, Journal of Solid State Electrochemistry 22 (2017) 317-329. https://doi.org/10.1007/s10008-017-3749-2

[13] J.M. Yun, J.S. Yeo, J. Kim, H.G. Jeong, D.Y. Kim, Y.J. Noh, S.S. Kim, B.C. Ku, S.I. Na, Solutionprocessable reduced graphene oxide as a novel alternative to PEDOT:PSS hole transport layers for highly efficient and stable polymer solar cells, Adv. Mater. 23 (2011) 4923-4928. https://doi.org/10.1002/adma.201102207

[14] I.P. Murray, S.J. Lou, L.J. Cote, S. Loser, C.J. Kadleck, T. Xu, J.M. Szarko, B.S. Rolczynski, J.E. Johns, J. Huang, L. Yu, L.X. Chen, T.J. Marks, M.C. Hersam, Graphene Oxide Interlayers for Robust, High-Efficiency Organic Photovoltaics, J. Phys. Chem. Lett. 2 (2011) 3006-3012. https://doi.org/10.1021/jz201493d

[15] S.H. Kim, C.H. Lee, J.M. Yun, Y.J. Noh, S.S. Kim, S. Lee, S.M. Jo, H.I. Joh, S.I. Na, Fluorinefunctionalized and simultaneously reduced graphene oxide as a novel hole transporting layer for highly efficient and stable organic photovoltaic cells, Nanoscale 6 (2014) 7183-7187. https://doi.org/10.1039/c4nr01038h

[16] O. Amargos-Reyes, I. Caballero-Quintana, J.L. Maldonado, J. Nicasio-Collazo, D. Romero-Borja, Single graphene derivative layer as a hole transport in organic solar cells based on PBDB-T:ITIC, Appl. Opt. 59 (2020) 8285-8292. https://doi.org/10.1364/AO.402510

[17] E. Yalcin, M. Can, C. Rodriguez-Seco, E. Aktas, R. Pudi, W. Cambarau, S. Demic, E. Palomares, Semiconductor self-assembled monolayers as selective contacts for efficient PiN perovskite solar cells, Energy Environ. Sci. 12 (2019) 230-237. https://doi.org/10.1039/c8ee01831f

[18] S. Casalini, C.A. Bortolotti, F. Leonardi, F. Biscarini, Self-assembled monolayers in organic electronics, Chem. Soc. Rev. 46 (2017) 40-71. https://doi.org/10.1039/c6cs00509h 
[19] R. Chauvin, “Carbomers". I. A general concept of expanded molecules, Tetrahedron Letters 36 (1995) 397-400. https://doi.org/10.1016/0040-4039(94)02275-g

[20] V. Maraval, R. Chauvin, From macrocyclic oligo-acetylenes to aromatic ring carbo-mers, Chem. Rev. 106 (2006) 5317-5343. https://doi.org/10.1021/cr050964e

[21] K. Cocq, C. Lepetit, V. Maraval, R. Chauvin, "Carbo-aromaticity" and novel carbo-aromatic compounds, Chem. Soc. Rev. 44 (2015) 6535-6559. https://doi.org/10.1039/c5cs00244c

[22] R. Chauvin, V. Maraval, K. Cocq, C. Barthes, A. Rives, Synthesis of Functional Carbo-benzenes with Functional Properties: The C2 Tether Key, Synlett 30 (2018) 30-43. https://doi.org/10.1055/s-00371610269

[23] L. Leroyer, C. Lepetit, A. Rives, V. Maraval, N. Saffon-Merceron, D. Kandaskalov, D. Kieffer, R. Chauvin, From hexaoxy-[6]pericyclynes to carbo-cyclohexadienes, carbo-benzenes, and dihydro-carbobenzenes: synthesis, structure, and chromophoric and redox properties, Chem. Eur. J. 18 (2012) 32263240. https://doi.org/10.1002/chem.201102993

[24] J. Cure, K. Cocq, A. Mlayah, T. Hungria, P. Alphonse, Y.J. Chabal, V. Maraval, R. Chauvin, A. Estève, C. Rossi, A triptych photocatalyst based on the Co-Integration of Ag nanoparticles and carbo-benzene dye into a TiO2 thin film, J. Hydrog. Energy 44 (2019) 26347-26360. https://doi.org/10.1016/j.ijhydene.2019.08.126

[25] I. Baglai, M. de Anda-Villa, R.M. Barba-Barba, C. Poidevin, G. Ramos-Ortiz, V. Maraval, C. Lepetit, N. Saffon-Merceron, J.L. Maldonado, R. Chauvin, Difluorenyl carbo-Benzenes: Synthesis, Electronic Structure, and Two-Photon Absorption Properties of Hydrocarbon Quadrupolar Chromophores, Chem. Eur. J. 21 (2015) 14186-14195. https://doi.org/10.1002/chem.201500482

[26] C. Zhu, T.H. Wang, C.J. Su, S.L. Lee, A. Rives, C. Duhayon, B. Kauffmann, V. Maraval, C.H. Chen, H.F. Hsu, R. Chauvin, 3D and 2D supramolecular assemblies and thermotropic behaviour of a carbobenzenic mesogen, Chem. Commun. 53 (2017) 5902-5905. https://doi.org/10.1039/c7cc02430d

[27] Z. Li, M. Smeu, A. Rives, V. Maraval, R. Chauvin, M.A. Ratner, E. Borguet, Towards graphyne molecular electronics, Nat. Commun. 6 (2015) 6321. https://doi.org/10.1038/ncomms7321

[28] A. Rives, I. Baglai, V. Malytskyi, V. Maraval, N. Saffon-Merceron, Z. Voitenko, R. Chauvin, Highly pi electron-rich macro-aromatics: bis(p-aminophenyl)-carbo-benzenes and their DBA acyclic references, Chem. Commun. 48 (2012) 8763-8765. https://doi.org/10.1039/c2cc34176j

[29] D. Listunov, O. Hammerich, I. Caballero-Quintana, A. Poater, C. Barthes, C. Duhayon, M.H. Larsen, J.L. Maldonado, G. Ramos-Ortiz, M.B. Nielsen, V. Maraval, R. Chauvin, Core carbo-mer of an Extended Tetrathiafulvalene: Redox-Controlled Reversible Conversion to a carbo-Benzenic Dication, Chem. Eur. J. (2020) 10707-10711. https://doi.org/10.1002/chem.202001700

[30] D. Barreiro-Arguelles, G. Ramos-Ortiz, J.-L. Maldonado, E. Perez-Gutierrez, D. Romero-Borja, A. Alvarez-Fernandez, PTB7:PC71BM-Based Solar Cells Fabricated With the Eutectic Alloy Field's Metal as an Alternative Cathode and the Influence of an Electron Extraction Layer, IEEE J. Photovolt. 7 (2017) 191-198. https://doi.org/10.1109/jphotov.2016.2617087

[31] O. Amargós-Reyes, J.-L. Maldonado, D. Romero-Borja, D. Barreiro-Argüelles, I. Caballero-Quintana, O. Barbosa-García, J.A. Gaspar, Organic photovoltaic cell analysis through quantum efficiency and scanning tunneling microscopy of the donor/blend as an active film, J. Mater. Sci. 54 (2018) 24272445. https://doi.org/10.1007/s10853-018-2956-2

[32] D. Romero-Borja, J.-L. Maldonado, O. Barbosa-García, M. Rodríguez, A. de León, S. Fernández, E. Pérez-Gutiérrez, Organic solar cells based on graphene derivatives and eutectic alloys vacuum-free deposited as top electrodes, Carbon 134 (2018) 301-309. https://doi.org/10.1016/j.carbon.2018.03.083

[33] K. Cocq, V. Maraval, N. Saffon-Merceron, R. Chauvin, Carbo-benzene's aromaticity, before and beyond: a tribute to Nozoe, Chem. Rec. 15 (2015) 347-361. https://doi.org/10.1002/tcr.201402091

[34] I. Caballero-Quintana, J.L. Maldonado, M.A. Meneses-Nava, O. Barbosa-García, J. ValenzuelaBenavides, A. Bousseksou, Semiconducting Polymer Thin Films Used in Organic Solar Cells: A Scanning Tunneling Microscopy Study, Adv. Electron. Mater. 5 (2019) 1800499. https://doi.org/10.1002/aelm.201800499 
[35] I. Caballero-Quintana, D. Romero-Borja, J.L. Maldonado, J. Nicasio-Collazo, O. Amargos-Reyes, A. Jimenez-Gonzalez, Interfacial Energetic Level Mapping and Nano-Ordering of Small Molecule/Fullerene Organic Solar Cells by Scanning Tunneling Microscopy and Spectroscopy, Nanomaterials 10 (2020) E427. https://doi.org/10.3390/nano10030427

[36] L. Polak, R.J. Wijngaarden, Two competing interpretations of Kelvin probe force microscopy on semiconductors put to test, Phys. Rev. B $93 \quad$ (2016) 195320. https://doi.org/10.1103/PhysRevB.93.195320

[37] F. Giannazzo, E. Schiliro, G. Greco, F. Roccaforte, Conductive Atomic Force Microscopy of Semiconducting Transition Metal Dichalcogenides and Heterostructures, Nanomaterials 10 (2020) 803. https://doi.org/10.3390/nano10040803

[38] P. Bampoulis, R. van Bremen, Q. Yao, B. Poelsema, H.J.W. Zandvliet, K. Sotthewes, Defect Dominated Charge Transport and Fermi Level Pinning in MoS2/Metal Contacts, ACS Appl. Mater. Interfaces 9 (2017) 19278-19286. https://doi.org/10.1021/acsami.7b02739

[39] L.M. Clavian, P.C. Rajesh Kumar, K.V. Anil Kumar, D.N. Rao, N.K. Shihab, S. Ganesh, Enhanced third order optical nonlinearity in ultrathin amorphous film of tetraphenyl-porphyrin in picosecond regime, Opt. Laser Technol. 119 (2019) 105642. https://doi.org/10.1016/j.optlastec.2019.105642

[40] M. Dongol, M.M. El-Nahass, A. El-Denglawey, A.F. Elhady, A.A. Abuelwafa, Optical Properties of Nano 5,10,15,20-Tetraphenyl-21H,23H-Prophyrin Nickel (II) Thin Films, Curr. Appl. Phys. 12 (2012) 1178-1184. https://doi.org/10.1016/j.cap.2012.02.051

[41] M.M. El-Nahass, A.F. El-Deeb, H.S. Metwally, H.E.A. El-Sayed, A.M. Hassanien, Influence of X-ray irradiation on the optical properties of iron (III) chloride tetraphenylporphyrin thin films, Solid State Sci. 12 (2010) 552-557. https://doi.org/10.1016/j.solidstatesciences.2010.01.004

[42] R.M. Barba-Barba, M. Chammam, G. Ramos-Ortiz, D. Listunov, J. Velusamy, M. Rodriguez, R. Carriles, C. Silva, C. Duhayon, B. Kauffmann, V. Maraval, R. Chauvin, Linear and nonlinear optical properties of a quadrupolar carbo-benzene and its benzenic parent: The carbo-merization effect, Dyes and Pigments 188 (2021) 109133. https://doi.org/10.1016/j.dyepig.2021.109133

[43] B. Xiao, A. Tang, L. Cheng, J. Zhang, Z. Wei, Q. Zeng, E. Zhou, Non-Fullerene Acceptors With A2 $=$ A1-D-A1 = A2 Skeleton Containing Benzothiadiazole and Thiazolidine-2,4-Dione for HighPerformance P3HT-Based Organic Solar Cells, Solar RRL 1 (2017) 1700166. https://doi.org/10.1002/solr.201700166

[44] C. Carter, M. Brumbach, C. Donley, R.D. Hreha, S.R. Marder, B. Domercq, S. Yoo, B. Kippelen, N.R. Armstrong, Small molecule chemisorption on indium-tin oxide surfaces: enhancing probe molecule electron-transfer rates and the performance of organic light-emitting diodes, J. Phys. Chem. B 110 (2006) 25191-25202. https://doi.org/10.1021/jp064061g

[45] V.M. Bermudez, A.D. Berry, H. Kim, A. Pique, Functionalization of indium tin oxide, Langmuir 22 (2006) 11113-11125. https://doi.org/10.1021/la061578a

[46] M.N. Alberti, S. Nowakowska, M.D. Tzirakis, J. Nowakowski, P. Fesser, W.B. Schweizer, A. Shchyrba, C. Thilgen, T.A. Jung, F. Diederich, Synthesis oftrans- $\mathrm{A}_{2} \mathrm{~B}_{2}$ - andtrans- $\mathrm{A}_{2} \mathrm{BC}$-Porphyrins with Polar 4'-(Dimethylamino)tolan-4-yl Substituents, and a Screening Protocol for Vapor-Phase Deposition on Metal Surfaces, Eur. J. Org. Chem. 2014 (2014) 5705-5719. https://doi.org/10.1002/ejoc.201402634

[47] F.S. Benneckendorf, S. Hillebrandt, F. Ullrich, V. Rohnacher, S. Hietzschold, D. Jansch, J. Freudenberg, S. Beck, E. Mankel, W. Jaegermann, A. Pucci, U.H.F. Bunz, K. Mullen, StructureProperty Relationship of Phenylene-Based Self-Assembled Monolayers for Record Low Work Function of Indium Tin Oxide, J. Phys. Chem. Lett. 9 (2018) 3731-3737. https://doi.org/10.1021/acs.jpclett.8b01242

[48] P.D. Taylor, D.A. Osborne, S.A. Tawfik, T. Morishita, M.J.S. Spencer, Tuning the work function of the silicene/4 x 4 Ag(111) surface, Phys. Chem. Chem. Phys. 21 (2019) 7165-7173. https://doi.org/10.1039/c9cp00424f

[49] K.Y. Law, Squaraine chemistry: effects of structural changes on the absorption and multiple fluorescence emission of bis[4-(dimethylamino)phenyl]squaraine and its derivatives, J. Phys. Chem. 91 (1987) 5184-5193. https://doi.org/10.1021/j100304a012 
[50] C. Zhu, A. Rives, C. Duhayon, V. Maraval, R. Chauvin, Lipidic Carbo-benzenes: Molecular Probes of Magnetic Anisotropy and Stacking Properties of $\alpha$-Graphyne, J. Org. Chem. 82 (2017) 925-935. https://doi.org/10.1021/acs.joc.6b02397

[51] C. Zhu, C. Duhayon, D. Romero-Borja, J.-L. Maldonado, G. Ramos-Ortíz, A. Saquet, V. Maraval, R. Chauvin, Hexaaryl-carbo-benzenes revisited: a novel synthetic route, crystallographic data, and prospects of electrochemical behavior, New J. Chem. 41 (2017) 3908-3914. https://doi.org/10.1039/c7nj00028f

[52] M. Chammam, I. Caballero-Quintana, D. Barreiro-Argüelles, O. Amargós-Reyes, Y. Aidibi, B. Kauffmann, C. Duhayon, J.L. Maldonado, G. Ramos-Ortíz, V. Maraval, R. Chauvin, Expanding the carbo-Benzene Chemical Space for Electron-Accepting Ability: Trifluorotolyl/Tertiobutyl Substitution Balance, Helv. Chim. Acta 102 (2019) e1900049. https://doi.org/10.1002/hlca.201900049

[53] T. Wagner, H. Beyer, P. Reissner, P. Mensch, H. Riel, B. Gotsmann, A. Stemmer, Kelvin probe force microscopy for local characterisation of active nanoelectronic devices, Beilstein J. Nanotechnol. 6 (2015) 2193-2206. https://doi.org/10.3762/bjnano.6.225

[54] A. Mutlu, M. Can, C. Tozlu, Performance improvement of organic solar cell via incorporation of donor type self-assembled interfacial monolayer, Thin Solid Films 685 (2019) 88-96. https://doi.org/10.1016/j.tsf.2019.05.064

[55] D. Wrana, K. Cieslik, W. Belza, C. Rodenbucher, K. Szot, F. Krok, Kelvin probe force microscopy work function characterization of transition metal oxide crystals under ongoing reduction and oxidation, Beilstein J. Nanotechnol. 10 (2019) 1596-1607. https://doi.org/10.3762/bjnano.10.155

[56] S.W. Button, J.M. Mativetsky, High-resolution charge carrier mobility mapping of heterogeneous organic semiconductors, Appl. Phys. Lett. 111 (2017) 083302. https://doi.org/10.1063/1.4999762

[57] O.G. Reid, K. Munechika, D.S. Ginger, Space charge limited current measurements on conjugated polymer films using conductive atomic force microscopy, Nano Lett. 8 (2008) 1602-1609. https://doi.org/10.1021/nl0801551

[58] D.A. Ramsey, K.C. Ludema, The influences of roughness on film thickness measurements by Mueller matrix ellipsometry, Rev. Sci. Instrum. 65 (1994) 2874-2881. https://doi.org/10.1063/1.1144631

[59] H. Lu, J. Wang, C. Xiao, X. Pan, X. Chen, R. Brunecky, J.J. Berry, K. Zhu, M.C. Beard, Z.V. Vardeny, Spin-dependent charge transport through 2D chiral hybrid lead-iodide perovskites, Sci. Adv. 5 (2019) eaay0571. https://doi.org/10.1126/sciadv.aay0571

[60] J. Niu, D. Yang, X. Ren, Z. Yang, Y. Liu, X. Zhu, W. Zhao, S. Liu, Graphene-oxide doped PEDOT:PSS as a superior hole transport material for high-efficiency perovskite solar cell, Org. Electron. 48 (2017) 165-171. https://doi.org/10.1016/j.orgel.2017.05.044

[61] C.C. Chang, J.H. Tao, C.E. Tsai, Y.J. Cheng, C.S. Hsu, Cross-linked Triarylamine-Based HoleTransporting Layer for Solution-Processed PEDOT:PSS-Free Inverted Perovskite Solar Cells, ACS Appl. Mater. Interfaces 10 (2018) 21466-21471. https://doi.org/10.1021/acsami.8b04396

[62] D. Zhang, J. Wang, X. Zhang, J. Zhou, S.-U. Zafar, H. Zhou, Y. Zhang, Sequential molecular doping of non-fullerene organic solar cells without hole transport layers, J. Mater. Chem. 8 (2020) 158-164. https://doi.org/10.1039/c9tc04969j

[63] A. Alnuaimi, I. Almansouri, A. Nayfeh, Effect of mobility and band structure of hole transport layer in planar heterojunction perovskite solar cells using 2D TCAD simulation, J. Comput. Electron. 15 (2016) 1110-1118. https://doi.org/10.1007/s10825-016-0850-1

[64] J. Cure, K. Cocq, A. Nicollet, K. Tan, T. Hungria, S. Assie-Souleille, S. Vivies, L. Salvagnac, M. Quevedo-Lopez, V. Maraval, R. Chauvin, A. Estève, C. Rossi, A Beehive Inspired Hydrogen Photocatalytic Device Integrating a Carbo-Benzene Triptych Material for Efficient Solar PhotoReduction of Seawater, Adv. Sustain. Syst. 4 (2020) 2000121. https://doi.org/10.1002/adsu.202000121

[65] A. Magomedov, A. Al-Ashouri, E. Kasparavičius, S. Strazdaite, G. Niaura, M. Jošt, T. Malinauskas, S. Albrecht, V. Getautis, Self-Assembled Hole Transporting Monolayer for Highly Efficient Perovskite Solar Cells, Adv. Ener. Mater. 8 (2018) 1801892. https://doi.org/10.1002/aenm.201801892 
[66] Y. Zhong, Q. Zhang, Y. Wei, Q. Li, Y. Zhang, Self-assembled monolayer modified copper(I) iodide hole transport layer for efficient polymer solar cells, Chinese Phys. B 27 (2018) 078802. https://doi.org/10.1088/1674-1056/27/7/078802

[67] S.Y. Kim, S.J. Cho, S.E. Byeon, X. He, H.J. Yoon, Self-Assembled Monolayers as Interface Engineering Nanomaterials in Perovskite Solar Cells, Adv. Energy Mater. 10 (2020) 2002606. https://doi.org/10.1002/aenm.202002606 